\title{
Coupling Effects of Yaw Damper and Wheel-Rail Contact on Ride Quality of Railway Vehicle
}

\author{
Hai Zhang $\mathbb{D}$, ${ }^{1,2}$ Xiangrui Ran $\mathbb{D}^{2},{ }^{2}$ Xiugang Wang $\mathbb{D},{ }^{3}$ Fengtao Lin $\mathbb{D}^{2}$, and Qi Jiang $\mathbb{D}^{2}$ \\ ${ }^{1}$ State Key Laboratory of Traction Power, Southwest Jiaotong University, Chengdu, Sichuan 610031, China \\ ${ }^{2}$ Key Laboratory of Ministry of Education for Conveyance and Equipment, East China Jiaotong University, Nanchang, \\ Jiangxi 330013, China \\ ${ }^{3}$ CRRC Qingdao Sifang Co., Ltd., Qingdao, Shandong 266111, China
}

Correspondence should be addressed to Xiangrui Ran; xiangruiran@ecjtu.edu.cn

Received 16 November 2020; Revised 20 February 2021; Accepted 25 March 2021; Published 9 April 2021

Academic Editor: Davood Younesian

Copyright (C) 2021 Hai Zhang et al. This is an open access article distributed under the Creative Commons Attribution License, which permits unrestricted use, distribution, and reproduction in any medium, provided the original work is properly cited.

\begin{abstract}
The ride quality of the railway vehicle is not only affected by the wheel-rail contact geometry but also by the yaw damper. In order to explore this variation law, an equivalent parameter model of the yaw damper was established based on the internal characteristics of the yaw damper, which is both accurate and efficient. Then, considering the influence of wheel wear and wheel-rail contact geometry, ride quality of the railway vehicle under different parameters of yaw damper and wheel-rail contact parameters was analysed. The results show that the wheel-rail contact points are scattered on the wheel profile after the wheel wears out, and the equivalent conicity also tends to increase with the increasing operating mileage. The distribution of ride quality space is sensitive to the change of equivalent conicity. In the low equivalent conicity area, the expansion rate of excellent ride quality space is faster. In the high equivalent conicity area, the expansion rate of qualified ride quality space is faster. Appropriate additional stiffness which is oil stiffness in parallel with structural damping in the equivalent parameter model of the yaw damper can improve the vehicle ride quality. The lateral ride quality is influenced obviously with the condition of the damping of the yaw damper being less than $440 \mathrm{kN} \cdot \mathrm{s} \cdot \mathrm{m}^{-1}$. Properly reducing the joint stiffness of the yaw damper could reduce the influence of characteristic parameters of the yaw damper and equivalent conicity of the wheel-rail contact on vehicle lateral ride quality. The optimized characteristic parameters of the yaw damper are used in the actual vehicle test, and the ride quality is effectively improved.
\end{abstract}

\section{Introduction}

China's CRH3 EMU demonstrated good lateral ride quality in the comprehensive performance test of the BeijingTianjin intercity and Wuhan-Guangzhou high-speed rail, with the maximum lateral Sperling index lower than 2.5. During the comprehensive test of the Beijing-Shanghai pilot section of the CRH380BL EMU, different degrees of lowfrequency lateral shaking of the frame and car body occurred. These phenomena indicate that the hunting of the EMU is intensified under high-speed operating conditions, which affects the ride quality of the vehicle and the comfort of passengers. The wheel-rail contact relationship deteriorates with the speed of railway vehicles increasing and wheel wear spreading, which results in poor contact characteristics between the wheel and rail $[1,2]$. Under this condition, the ride quality of the vehicle is reduced and the passenger comfort is also greatly reduced.

The vehicle is excited by the external excitations during operation to generate vibration. Among the external excitations, the vehicle vibration caused by the lateral irregularity of the rail is more prominent, and the vehicle vibration affects the ride quality of the vehicle. During the operation of the vehicle, the continuous friction between the wheels and the rail leads to material loss, which is called wear. The wear of the contact surface leads to changes in the geometry of the surface of the wheel tread and the rail. The geometric state of the contact point between the wheel and the rail is called the wheel-rail contact geometry. Wheel-rail contact geometry, an important characteristic parameter to solve the problem of railway 
dynamics, affects the vehicle ride quality, curve negotiation, and track and vehicle safety under external excitation from track irregularity $[3,4]$. The force between the wheel and rail is changed with the change of wheel-rail contact geometry, which will change the external excitation of the vehicle system accordingly. As it can be seen from the phenomenon of increased hunting motion in the operation of railway vehicles, changes in the amplitude and frequency of the relative operation between the suspension components and the car body will be caused by the poor wheel-rail contact patterns [5], which results in an increase in the possibility of vehicle derailment. Yaw damper, a key component of the secondary suspension connecting the car body and frame, can effectively absorb and alleviate the vibration and impact caused by the change of the wheel-rail relationship, improve the bad contact state between the wheel and the rail, and significantly reduce the lateral vibration of the railway vehicle bogie and the car body so that the vehicle ride quality could be improved [6]. The increase in vehicle operating speed changes the wheel-rail contact geometry, intensifies the vibration of the car body and the frame [7-10], and then changes the working conditions of the both ends of the yaw damper. The yaw damper alleviates the vibration between the car body and the frame, which reduces the contact between the wheel flange and the rail and improves the wheel-rail contact geometry $[11,12]$. The coupling effect of the two affects the ride quality of vehicle operation.

Research studies carried out by domestic and foreign scholars are roughly divided into two categories. One is to discuss the method of establishing yaw damper models. Yu et al. [13] established the yaw damper based on the stability of vehicle motion and curve passing. Alonso et al. [14] proposed a new yaw damper model, which verified that the model reduced the calculation cost while ensuring the calculation accuracy. Besinger et al. [15] proposed a nonlinear equivalent parameter model of the yaw damper and verified that it can be used for relevant calculations under real conditions. Richard [16] proposed a new type of secondary lateral shock absorber model based on the magic formula. The other is to explore the influence of the characteristic parameters of the yaw damper on the running state of the vehicle. Jin et al. [17] tested the vehicle dynamics index under different working conditions, and it was concluded that adjusting the damping value of the yaw damper could better adapt the vehicle to different conditions. Besides, the influence of the combined damping of the yaw damper and secondary lateral damper on the stability of the vehicle was analysed, and the damping value of the yaw damper should be appropriately increased, while reducing the damping value of the secondary lateral damper [18]. Qin et al. [19] studied the influence of the stiffness and damping characteristics of the rubber joint stiffness of yaw dampers and secondary lateral dampers on vehicle operation through dynamic simulation and proposed that the optimal value of the stiffness of the joint stiffness of yaw dampers is between 10 and $12 \mathrm{MN} \cdot \mathrm{m}^{-1}$. Xia et al. [20] derived the analytical formula of the damping force transfer function of the yaw damper and analysed the influence of the yaw damper parameters and installation position on the vehicle stability.
The above research studies indicate that the stability and ride quality of the railway vehicle could be improved to a certain extent by adjusting the characteristic parameters of yaw dampers. However, these studies only focus on the effect of yaw dampers on vehicle stability under specific wheel-rail contact conditions, and the coupling effect of yaw dampers with wheel-rail contact on vehicle ride quality has not been considered. There are still few studies on how the characteristic parameters of yaw dampers affect vehicle ride quality under different wheel-rail contact states affected by wheel wear, which have a significant impact on whether the vehicle could run stably in the real environment. Current research studies on vehicle ride quality mostly observe which level the index of ride quality belongs to under a certain condition and lack the analysis of the changing trend and speed of ride quality of each level with changes in parameter conditions. The research in this paper fully fills the abovementioned research vacancies and focuses on the changing laws of vehicle ride quality under the coupling effect of yaw damper and wheel-rail contact geometry. Compared with the existing literature, this paper gives the complete change law of the vehicle ride quality with the change of the equivalent conicity. Besides, this paper also analyses the change law of the vehicle ride quality of different grades and the characteristic parameters of the yaw damper and the equivalent conicity, which include a trend evaluation from the perspective of sensitivity for auxiliary evaluation. The results of the paper provide theoretical support for the practical application of the railway vehicle.

The objective of this work is to obtain the law of vehicle ride quality affected by the coupling effect of the yaw damper and wheel-rail contact. The idea is to establish an equivalent parameter model of the yaw damper, embed the model into the vehicle model, and explore the coupling effect by adjusting the characteristic parameters of yaw damper and wheel-rail contact. To achieve this objective, in the first step, the characteristics of typical structures of the yaw damper are studied. Secondly, an equivalent parameter model of the yaw damper is established, and the mathematical expressions of the damping force and characteristic parameters are derived. The equivalent parameter model is embedded into the vehicle model, and the simulation results are compared with the test to determine the rationality and accuracy of the two models. Then, the effect of wheel wear on the change of wheel-rail contact geometry is analysed to obtain the law of wheel tread taper change. Finally, the vehicle's lateral ride quality space under the coupling effect of yaw damper and wheel-rail contact geometry at different vehicle speeds are calculated so that the variation law of the vehicle's lateral ride quality with the characteristics of the yaw damper and the wheel-rail contact is obtained. At the same time, the characteristic parameters of the yaw damper are optimized, which are verified in the actual vehicle test.

\section{General Description of the Yaw Damper}

Yaw damper is installed between the frame and car body or bolster through the joint connecting structure (Figure 1) and relies on the oil to flow through the internal damping valve 


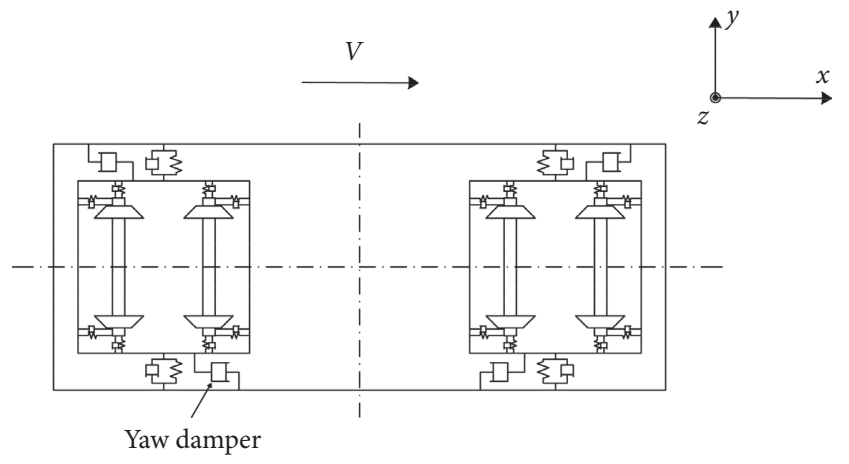

FIgURE 1: Installation position of the yaw damper.

to generate damping force, thereby suppressing the hunting motion of the bogie.

The most important structure of a typical yaw damper is the damping valve, piston check valve, foot check valve, and joint connecting structure (Figure 2). The damping valve is mainly composed of a valve seat, a movable heart valve, a spring, and an adjusting nut; the piston check valve and the foot check valve are both composed of a valve body, a valve plate, and a spring. The internal chamber of the yaw damper is divided by the three valves into three parts: the rebound chamber, the compression chamber, and the auxiliary chamber. The damping valve connects the auxiliary chamber and the rebound chamber. Also, the rebound chamber is connected to the compression chamber by the piston check valve. In the similar way, the compression chamber is connected to the auxiliary chamber by the foot check valve. The joint connection structure is mainly made of rubber. When the car body and the bogie move relative to each other, the joint connection structure is stretched or compressed, resulting in a larger stiffness value due to the characteristics of the rubber material.

The working principle of the yaw damper is shown in Figure 3. The piston vibrates in the oil chamber with the relative vibration between the connecting parts at the two ends. During the rebound stroke, the piston makes a rebound motion with the bogie and the car body moving away from each other laterally. During the compression stroke, the piston makes compression motion with the bogie and the car body approaching laterally.

In the rebound stroke, the relative displacement between the car body and the bogie is transmitted by the joint connection structure to the piston rod. The piston check valve is closed, and the volume of the rebound chamber is reduced by $A$. At this time, the corresponding volume of oil is pressed from the rebound chamber into the auxiliary chamber through the damping valve, thereby generating working damping force. As the piston rebounds, the volume of the compression chamber increases by $A+B$, and the foot check valve is opened. The same volume of oil is replenished from the auxiliary chamber to the rebound chamber through the foot check valve.

In the compression stroke, the relative displacement between the car body and the bogie is also transmitted by the joint connection structure to the piston rod. As the piston check valve is opened, the volume of the rebound chamber is increased by $A$ and the volume of the compression chamber is reduced by $A+B$. At this time, the corresponding $A+B$ volume of oil is pressed from the compression chamber into the rebound chamber through the piston check valve, while the excess $B$ volume of oil is pressed from the rebound chamber into the auxiliary chamber through the damping valve, thereby generating a working damping force.

After the piston rod being externally excited, a certain force will be exerted on the piston because of a certain viscosity and compressibility of the oil inside the damper. This force is similar with the effect of installing a spring between the piston and the cylinder. To sum up, the external force of the yaw damper is formed by damping force and elastic force provided by the joint connection structure and oil, respectively.

It is because the damping characteristics of the yaw damper are affected by its internal structure, oil characteristics and other physical parameters that the parameters introduced when building the model should be carefully selected. If there are too many parameters, the calculation efficiency will be reduced, while too few parameters will cause the model accuracy to decrease.

\section{Modeling of the Yaw Damper}

There are three ways to establish the yaw damper model. The first is to establish a model through the mathematical description of the oil and fluid flow in the damper, such as the Lang model. The second is the equivalent linear model established by linear second-order differential equations, such as the Wallaschek [21] and the Genta and Campanile [22] model. The third is the equivalent parameter model established by function description based on the characteristic parameters obtained from the experiment such as the Schiehlen and $\mathrm{Hu}$ [23], the Maxwell, and the Kelvin-Voigt model.

There are no physical meanings for the parameters described by the third model. However, for its equivalent parameters, there is a strong correlation with the damper experiment data, which means the characteristics of damping and stiffness of the yaw damper could be better reflected by this type of model so that the interference of complicated parameters could be avoided.

According to the analysis of the internal characteristics of the yaw damper, the oil stiffness is equivalent to installing a spring between the piston and the cylinder, which is called as additional stiffness. The excitation of the spring should be the same as that of the piston. Therefore, when modeling, the additional stiffness $k_{c}$ and the structural damping care connected in parallel, and then, the structure is connected in series with the joint stiffness $K$ to obtain the equivalent parameter model shown in Figure 4. In order to simplify the form of the final expression, $k$ is used to represent the joint stiffness of the rubber connection device at both ends of the yaw damper in series with the car body and frame (i.e., $k=0.5 K)$.

Assuming that the end of the piston rod is excited by a sinusoidal displacement signal $y$ represented by equation 


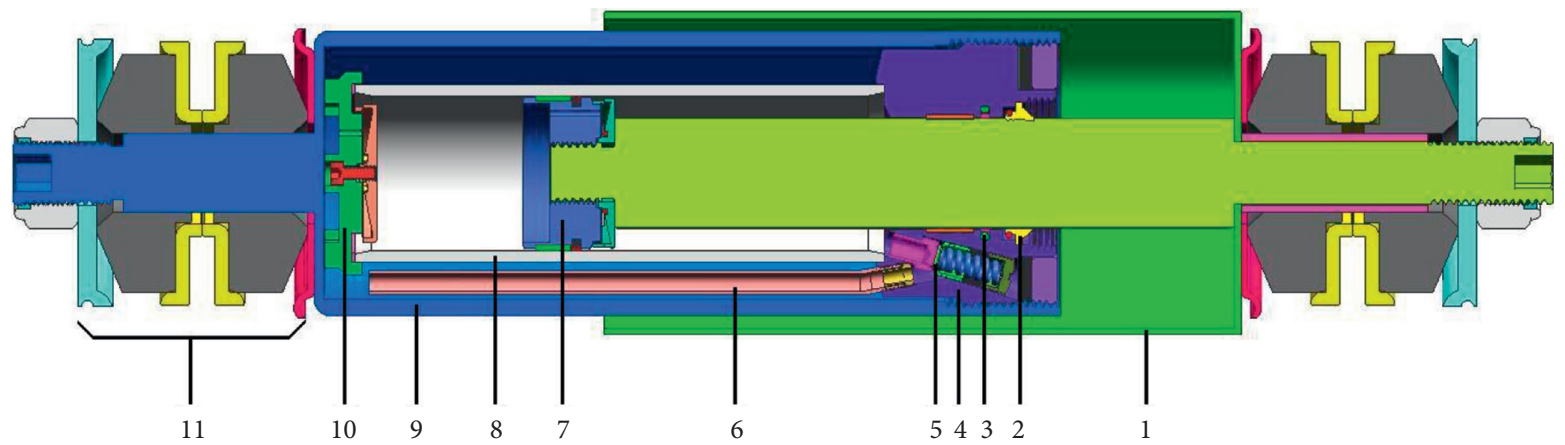

Figure 2: Internal structure of the yaw damper. (1) Protective cover. (2) Oil scraper ring. (3) Piston rod sealing device. (4) Piston rod orientation seat. (5) Damping valve. (6) Oil orientation tube. (7) Piston and piston rod composition. (8) Pressure cylinder. (9) Auxiliary chamber. (10) Foot check valve. (11) Joint connection structure.

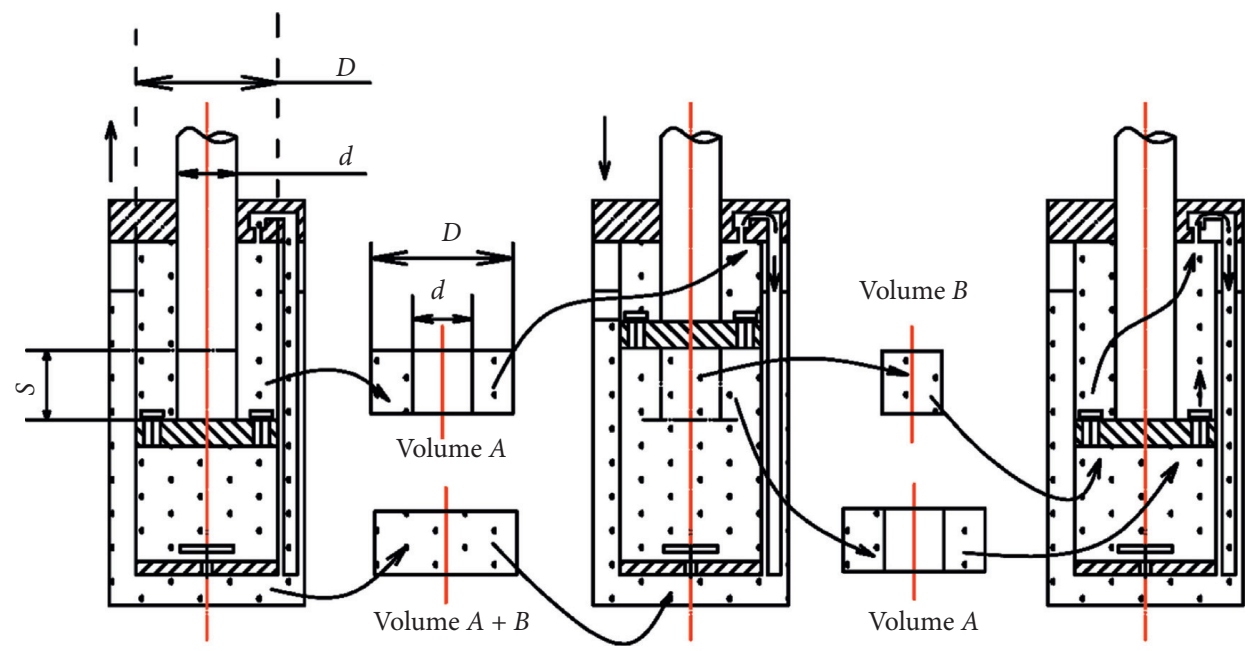

FIGURE 3: Working principle of the yaw damper.

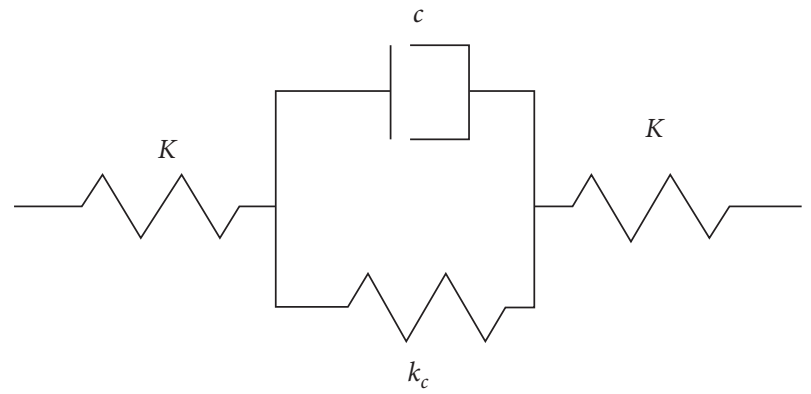

Figure 4: Equivalent parameter model.

(1), $\mathrm{m}$ and $y_{1}$ are, respectively, supposed as the mass and displacement of the piston. Then, the entire model can be described as

$$
\begin{aligned}
y & =A \sin (w t), \\
\mathrm{m} \cdot y_{1}^{\prime} & =k \cdot\left(y-y_{1}\right)+k_{c} \cdot y_{1}+c \cdot y_{1}^{\prime},
\end{aligned}
$$

where $y_{1}^{\prime}$ is the velocity of the piston rod, $w$ is frequency, $A$ is amplitude, $c$ is the structural damping, and $k_{c}$ is the additional stiffness. Taking into account that the mass of the piston is very small, the inertial term $\mathrm{m} \cdot y_{1}^{\prime \prime}$ in equation (2) is much smaller than the other two items so that it could be ignored, which means equation (2) could be simplified as

$$
k \cdot\left(y-y_{1}\right)+k_{c} \cdot y_{1}+c \cdot y_{1}^{\prime}=0 .
$$

When the end of the piston rod is excited by the sinusoidal displacement signal, the piston displacement and velocity $y_{1}^{\prime}$ should be the harmonic response. Actually, they could be described as

$$
\begin{aligned}
& y_{1}=A_{1} \sin (w t-\alpha), \\
& y_{1}^{\prime}=A_{1} w \cos (w t-\alpha),
\end{aligned}
$$

where $A_{1}$ and $\alpha$ are, respectively, the displacement of the piston and the phase difference between $y$ and $y_{1}$.

Equations (6) and (7) are obtained by substituting equation (1) into equation (3). Besides, equations (6) and (7) could also be transformed into the form of equations (4) and (5) by basic trigonometric function transformation, which is a purely mathematical problem so that it will not be discussed here: 


$$
\begin{aligned}
& y_{1}=\frac{k\left(k-k_{c}\right) A}{\left(k-k_{c}\right)^{2}+(c w)^{2}} \sin (w t)-\frac{k c w A}{\left(k-k_{c}\right)^{2}+(c w)^{2}} \cos (w t), \\
& y_{1}^{\prime}=\frac{k\left(k-k_{c}\right) A w}{\left(k-k_{c}\right)^{2}+(c w)^{2}} \cos (w t)+\frac{k c w^{2} A}{\left(k-k_{c}\right)^{2}+(c w)^{2}} \sin (w t) .
\end{aligned}
$$

By incorporating equation (7), the equivalent parameters' model damping force expression can be described as

$$
\begin{aligned}
F= & \frac{k A\left[(c w)^{2}+k_{c}\left(k-k_{c}\right)\right]}{\left(k-k_{c}\right)^{2}+(c w)^{2}} \sin (w t) \\
& +\frac{A w c\left[k\left(k-k_{c}\right)-k \cdot k_{c}\right]}{\left(k-k_{c}\right)^{2}+(c w)^{2}} \cos (w t) .
\end{aligned}
$$

When combining equation (8) with the displacement and velocity excitation formulas, the equivalent stiffness $K_{e}$ and equivalent damping $C_{e}$ of the equivalent parameters' model could be, respectively, described as

$$
\begin{aligned}
& K_{e}=\frac{k\left[(c w)^{2}+k_{c}\left(k-k_{c}\right)\right]}{\left(k-k_{c}\right)^{2}+(c w)^{2}}, \\
& C_{e}=\frac{c\left[k\left(k-k_{c}\right)-k \cdot k_{c}\right]}{\left(k-k_{c}\right)^{2}+(c w)^{2}} .
\end{aligned}
$$

\section{Model Results}

In order to determine the rationality and accuracy of the model, the damping characteristic parameters of the yaw damper of CRH380 B were substituted into the model to perform dynamic simulation. According to the technical requirements of the Ministry of Railways of China: TB/ T1481-2004, the excitation frequency was set to the main excitation frequency of the vehicle frame as $4 \mathrm{~Hz}$. Figure 5 shows the indicator diagram obtained by model simulation and test. It can be seen that the indicator diagrams of simulation and experiment are very similar. Table 1 shows the damping force and relative error obtained from model simulation and test. It can be seen that the relative error between the simulated damping force and the test damping force is very small: the maximum is $9.56 \%$, and the minimum is only $0.03 \%$, which means the established equivalent parameter model is rational and accurate.

In the dynamic simulation software UM, a 50-degree-offreedom vehicle dynamics model based on the parameters of the CRH380 B vehicle is built (Figure 6). The car body, frame, and axle box are all rigid bodies. Considering the flexibility of the car body in the model will be more in line with the actual situation of the vehicle [24]. In order to simplify the calculation, this model still uses a rigid car body. The primary spring and secondary air spring are set to linear force. The damper, the traction connecting rod, and the lateral stopping block are all bipolar forces. The positioning rotary arm and the antiroll bar are set to the bushing model.
The track is set to a straight line condition, and the irregularity is set to measure irregularity of the WuhanGuangzhou line. Besides, the wheel-rail creep force is set to the FASTSIM model. The vehicle running speed is set to $300 \mathrm{~km} \cdot \mathrm{h}^{-1}$. The yaw damper is set as the equivalent parameter model. The calculated variable is set to the lateral acceleration of the car body and frame. Cosimulation is carried out to determine whether the effect of equivalent parameters on the vehicle is in line with the actual situation. Figure 7 shows the comparison between the simulation and test vibration acceleration of the car body and frame in the frequency domain. It can be seen that the results of the cosimulation are roughly consistent with the test results. The amplitude of vibration acceleration is slightly lower than the test, for there are fewer interference factors in the simulation. The model can better reflect the actual situation of vehicle operation and can be used for further research.

In summary, the equivalent parameter model and the combined model of the yaw damper basically meet the actual needs and can be used for further research.

\section{Analysis of the Wheel-Rail Contact State}

As the wheel moves laterally on the rail, the contact point between the wheel and the rail also changes. Both the wornout wheel tread and the upper surface of the rail have a certain curvature, and the change of the contact point is often not continuous. Therefore, the state of the wheel-rail contact geometry has a greater impact on the displacement of the contact point. At the same time, the wheels and rails will wear out during vehicle operation, and the geometric state of the contact surface will change accordingly, which will affect the ride quality of the vehicle. Figure 8 shows the distribution of wheel-rail contact points on the wheel tread under different wheel wear. It can be seen that when the wheel wear is low, the wheel-rail contact points are more concentrated on the wheel tread with small wheel-set lateral displacement. The wheel-rail contact points are gradually distributed on the wheel tread with the wheel wear increasing and appearing in skipping distribution after the wheels are worn to a certain extent, which means that local dents appear on the wheel tread as wheel wear increases.

In order to describe this change of wheel wear, the equivalent conicity is often used to characterize the wear of the wheel tread. Equivalent conicity is the main index of track, vehicle, and multibody dynamics simulation calculation, vehicle performance evaluation, or acceptance test. This important index is calculated by equation (11) in the system dynamics of railway vehicles and track:

$$
\lambda_{e}=\frac{\left|r_{L}-r_{R}\right|}{2 y_{w}}
$$

where $r_{L}$ and $r_{R}$ are, respectively, rolling circle radius of left and right wheels and $y_{w}$ is the lateral displacement of the wheel-set center away from the centering position.

Import the data of measured wear of LMB wheel treads and CN60 rail into UM, and then, calculate the equivalent conicity of the wheel-rail contact point corresponding to the 


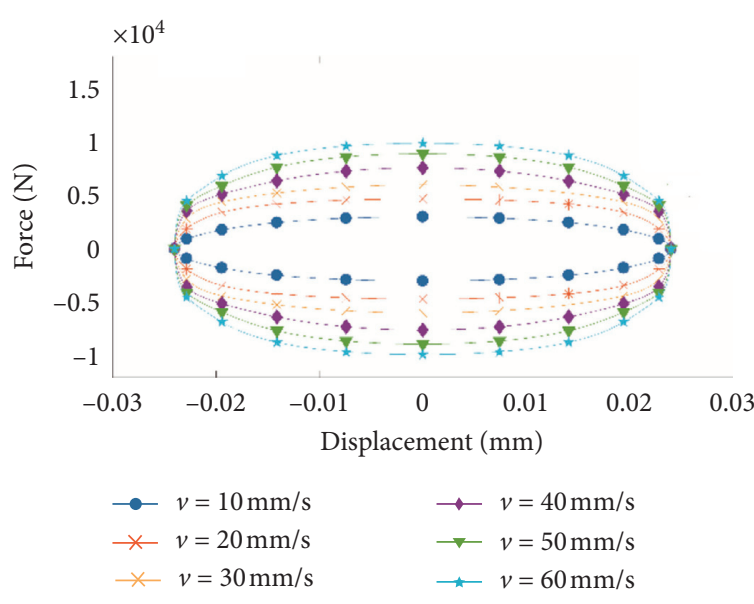

(a)

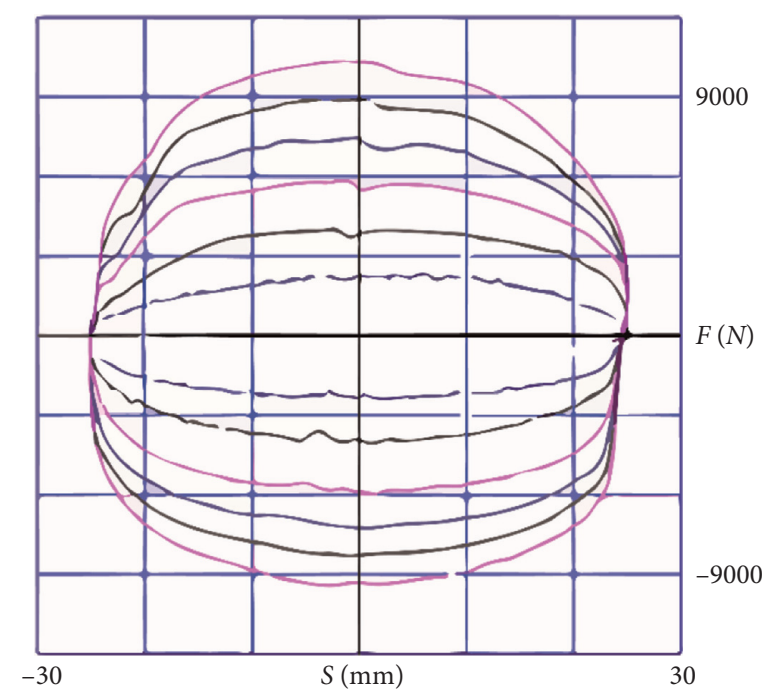

(b)

FiguRe 5: Indicator diagram comparison of the model and test of the yaw damper. (a) Model indicator diagram. (b) Test indicator diagram.

TABLE 1: Comparison table between simulation and experiment of the yaw damper.

\begin{tabular}{|c|c|c|c|c|c|c|}
\hline Speed $(\mathrm{mm} / \mathrm{s})$ & $\begin{array}{l}\text { Model maximum } \\
\text { rebound force }(\mathrm{N})\end{array}$ & $\begin{array}{l}\text { Test maximum } \\
\text { rebound force }(\mathrm{N})\end{array}$ & Relative error (\%) & $\begin{array}{c}\text { Model maximum } \\
\text { compression force }(\mathrm{N})\end{array}$ & Test & $\begin{array}{c}\text { maximum } \\
\text { compression force } \\
(\mathrm{N})\end{array}$ \\
\hline \multicolumn{7}{|l|}{$\begin{array}{l}\text { Relative } \\
\text { error (\%) }\end{array}$} \\
\hline 10 & 3002 & 2959 & 1.45 & -3002 & 2880 & 4.23 \\
\hline 20 & 4687 & 4685 & 0.04 & -4687 & 4481 & 4.59 \\
\hline 30 & 5993 & 5990 & 0.05 & -5993 & 6035 & -0.53 \\
\hline 40 & 7583 & 7580 & 0.04 & -7583 & 7352 & 3.14 \\
\hline 50 & 8899 & 8896 & 0.03 & -8899 & 8125 & 9.52 \\
\hline 60 & 9884 & 9880 & 0.04 & -9884 & 9150 & 8.02 \\
\hline
\end{tabular}

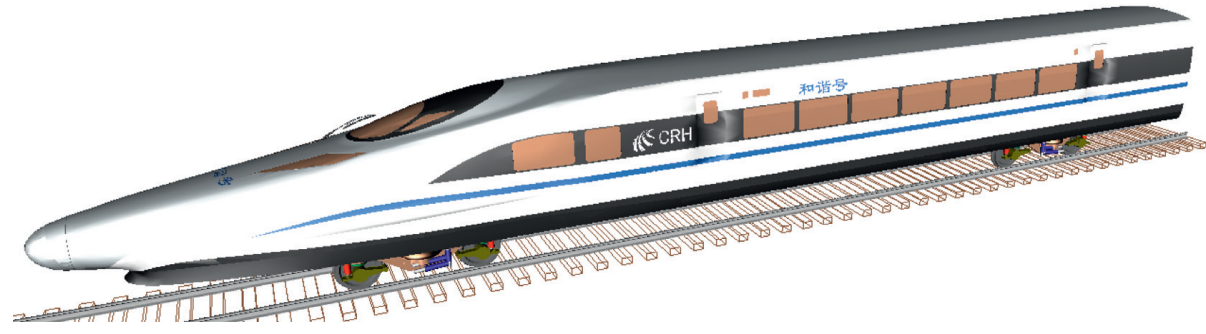

Figure 6: Vehicle dynamics model.

lateral displacement of different wheel sets. Figure 9 shows the change of the equivalent conicity of the wheel tread with the lateral displacement of the wheel-set under different wear conditions. It can be seen that, with the increase of vehicle operating mileage, the wheel wear condition becomes more severe. Within the range of wheel-set lateral displacement between 0 and $5 \mathrm{~mm}$, the equivalent conicity becomes larger with the wear condition increasing, which is also similar with the distribution of rail contact points in Figure 8. Figure 10 shows the change of the nominal equivalent conicity of the wheel with the wear of the wheel tread. It can be seen that, with the increase in wear, the nominal equivalent conicity of the wheel tread shows a trend of rapid increase in the initial stage and slower increase in 


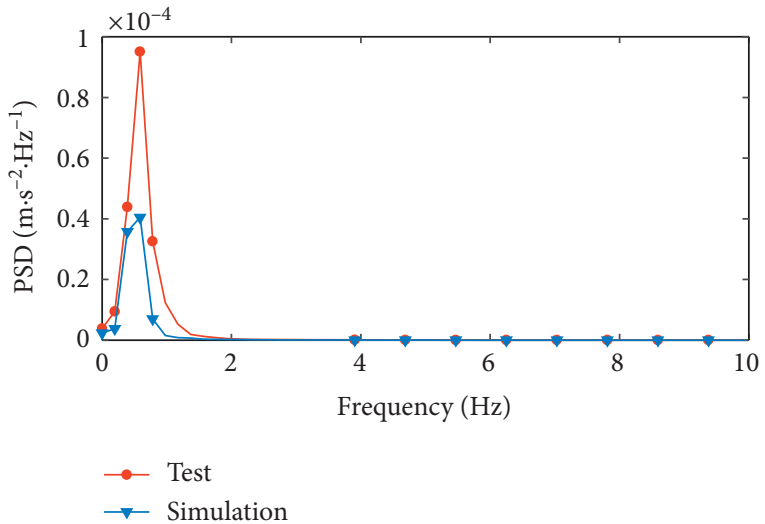

(a)

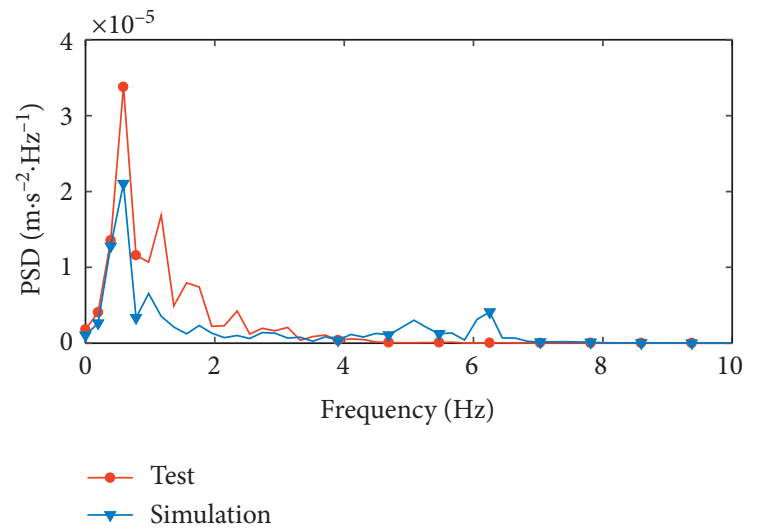

(b)

FIgURE 7: Comparison of vibration acceleration between simulation and test. (a) Car body. (b) Bogie.

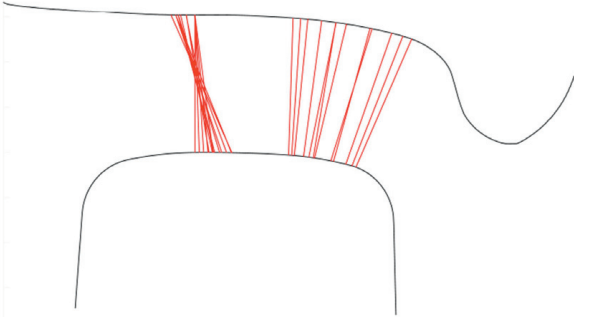

(a)

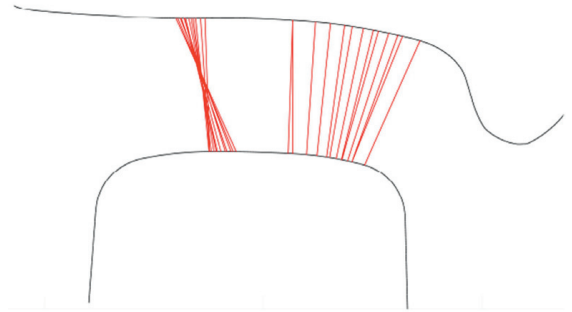

(c)

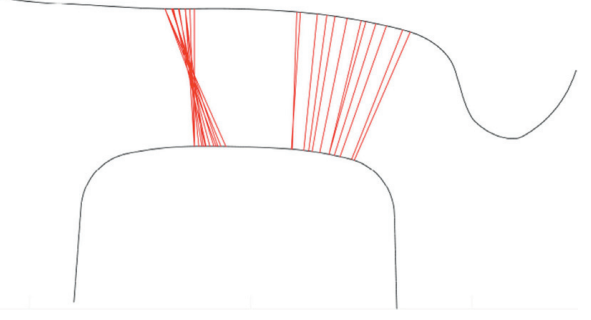

(b)

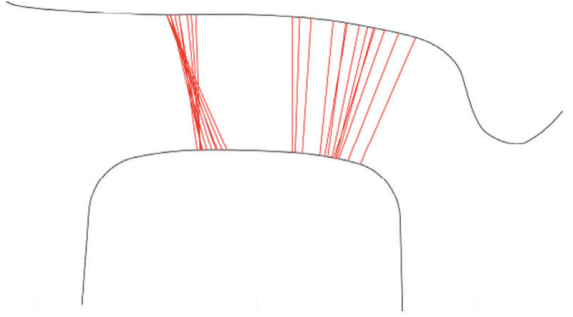

(d)

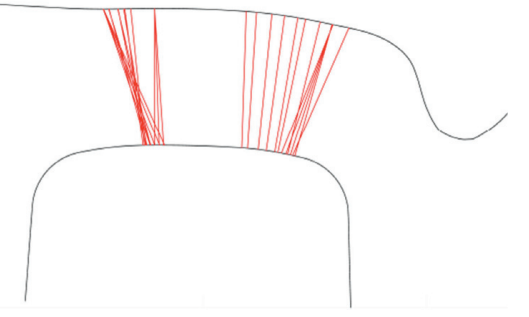

(e)

FIGURE 8: Distribution of wheel-rail contact points on the tread surface under different wheel wear. (a) 12.09 miriad milimetre (left). (b) 16.06 miriad milimetre (left). (c) 18.63 miriad milimetre (left). (d) 21.9 miriad milimetre (left). (e) 28.4 miriad milimetre (left).

the later stage, which means that, after the wheel tread is worn to a certain degree, it can maintain a relatively stable profile.

From the above analysis, it can be seen that the change of the equivalent conicity can better reflect the change of the wheel-rail contact geometry state. Vehicle ride quality could be improved if equivalent conicity is maintained within a certain range.

\section{Coupling Effects of Yaw Damper and Wheel- Rail Contact Geometry}

In the research on the ride quality of vehicles, the commonly used evaluation indexes are the Sperling index, the ISO2631 standard, and the car body vibration acceleration. The Sperling index and car body vibration acceleration are mainly used in China to evaluate the ride quality of vehicles. 


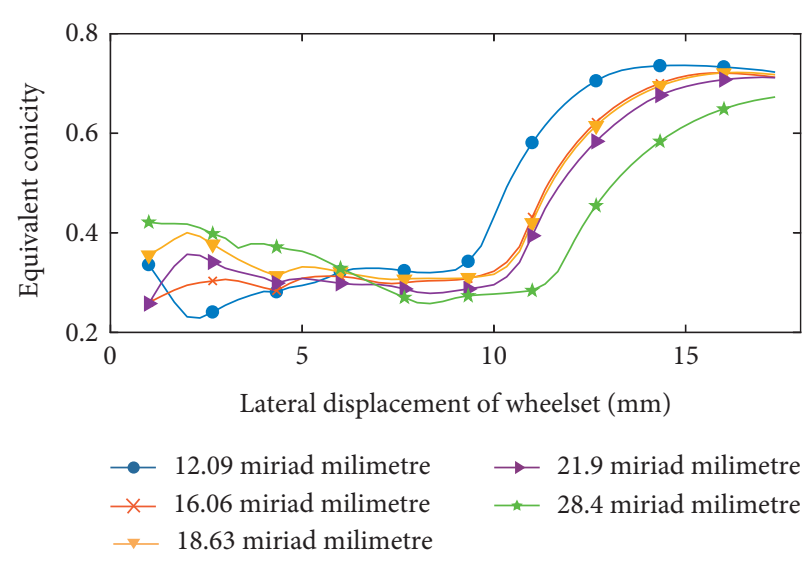

FIgURE 9: Comparison of the equivalent conicity under different wheel wear conditions with lateral displacement of the wheel set.

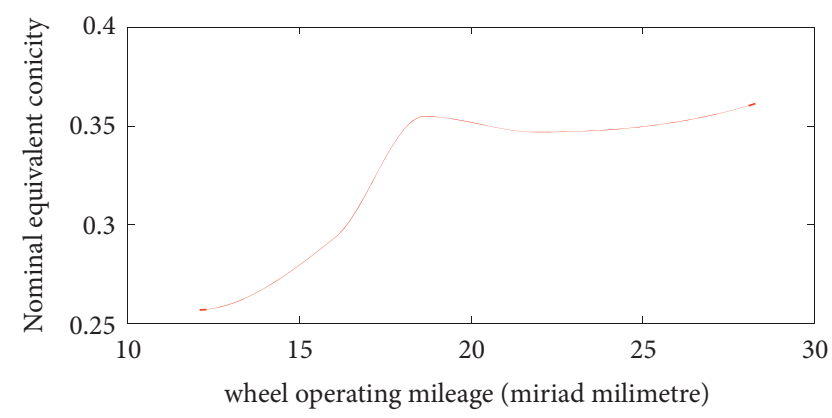

Figure 10: Nominal equivalent conicity under different wheel wear conditions.

Among them, the Sperling index uses a single criterion to quantitatively evaluate the ride quality of the vehicle, which is convenient for engineering application. In this paper, the Sperling index is selected to determine the ride quality of the vehicle. In addition, the Hopf bifurcation diagram is often used in the research of rail vehicle dynamics to indicate the stability of the vehicle, that is, the speed at which the vehicle will appear to be hunting instability. In the vehicle ride quality analysis, the bifurcation theory can be used to analyse the stability of the vehicle operation firstly, and then, the variation of the ride quality of the vehicle can be analysed under the stable condition of the vehicle, but it is not the focus of this paper so that it will not be discussed in detail.

The Sperling index was proposed by Helberg and Sperling of the German Federal Railways. It uses a single criterion to evaluate the ride quality of vehicles. Its basic formula can be described as

$$
W=0.896 \sqrt[10]{\frac{\alpha^{3}}{f}},
$$

where $\alpha$ is acceleration and its unit is $\mathrm{cm} \cdot \mathrm{s}^{-1}$ and $f$ is vibration frequency and its unit is $\mathrm{Hz}$.

Since the vehicle is subjected to random excitations during operation, its acceleration and frequency change with time. When calculating, it is necessary to group the acceleration waveforms by frequency, calculate the values of each group of accelerations, and then process them according to the following equation to obtain the final index:

$$
W=\sqrt[10]{\sum_{i=1}^{n} W_{i}^{10},}
$$

where $n$ is the number of groups and $W_{i}$ is the calculated value of each group.

According to the Sperling index, the degree of the ride quality of railway passenger cars in China can be divided into four grades: excellent, good, qualified, and unstable (Table 2). In order to simplify the calculation results, the good and qualified grades are combined into qualified grades. Therefore, the classification of vehicle ride quality in this paper is set as excellent, qualified, and unstable. Changes in vehicle ride quality and sensitivity to influencing parameters can be intuitively presented in the vehicle ride quality space. Vehicle ride quality space is defined as the distribution area of vehicle ride quality in consideration of multiple factors. Sensitivity is defined as the degree to which the dependent variable changes with the independent variable. When the independent variable changes to a fixed value, the greater the degree of change of the dependent variable is and the greater the sensitivity of the dependent variable to the independent variable is. At this time, adjusting the value of the independent variable can obviously change the value of the dependent variable so that the optimization is easier to be facilitated. In this paper, sensitivity analysis is only used as a change trend analysis, without quantitative analysis.

Based on the established cosimulation model in the UM software, change the characteristic parameters of the yaw damper, adopt cone-tread wheels with different equivalent conicity, and set the parameters such as track and wheel-rail contact force as in Section 4. The joint stiffness of the yaw damper is set to 25 and $70 \mathrm{MN} \cdot \mathrm{m}^{-1}$, the additional stiffness is set to 0,4 , and $8 \mathrm{MN} \cdot \mathrm{m}^{-1}$, and the structural damping is set to $0,110,220,330,440$, and $550 \mathrm{kN} \mathrm{s} \mathrm{m}^{-1}$. Besides, the vehicle running speed is set in the range between 10 and $500 \mathrm{~km} \cdot \mathrm{h}^{-1}$, and the equivalent conicity range of the wheel tread is set in the range between 0.01 and 0.5 . The calculation is divided into 6 large groups according to the value of joint stiffness and additional stiffness, and then, each large group is divided into 6 groups according to the value of structural damping. The calculation is performed in accordance with the process shown in Figure 11. The results obtained are shown in Figures 12-17. The red, yellow, and white areas correspond to the vehicle ride quality space of excellent, qualified, and unstable, respectively. It is impossible to calculate the Sperling index uniformly in the case of vehicle derailment. When the Sperling index is far greater than 3, there is no substantial significance to discuss the change of its value. In order to facilitate the observation of the vehicle ride quality space, this paper sets the upper limit of the Sperling index of the calculation result to 5 .

Figure 12 shows the calculation results of the joint stiffness being $70 \mathrm{MN} \cdot \mathrm{m}^{-1}$ and the additional stiffness being 0 . As the vehicle speed increases, the lateral Sperling index 
TABLE 2: China's vehicle running Sperling index and grade.

\begin{tabular}{lcc}
\hline Sequence & Sperling index & Assessment \\
\hline 1 & $<2.5$ & Excellent \\
2 & $2.5-2.75$ & Good \\
3 & $2.75-3$ & Qualified \\
4 & $>3$ & Unstable \\
\hline
\end{tabular}

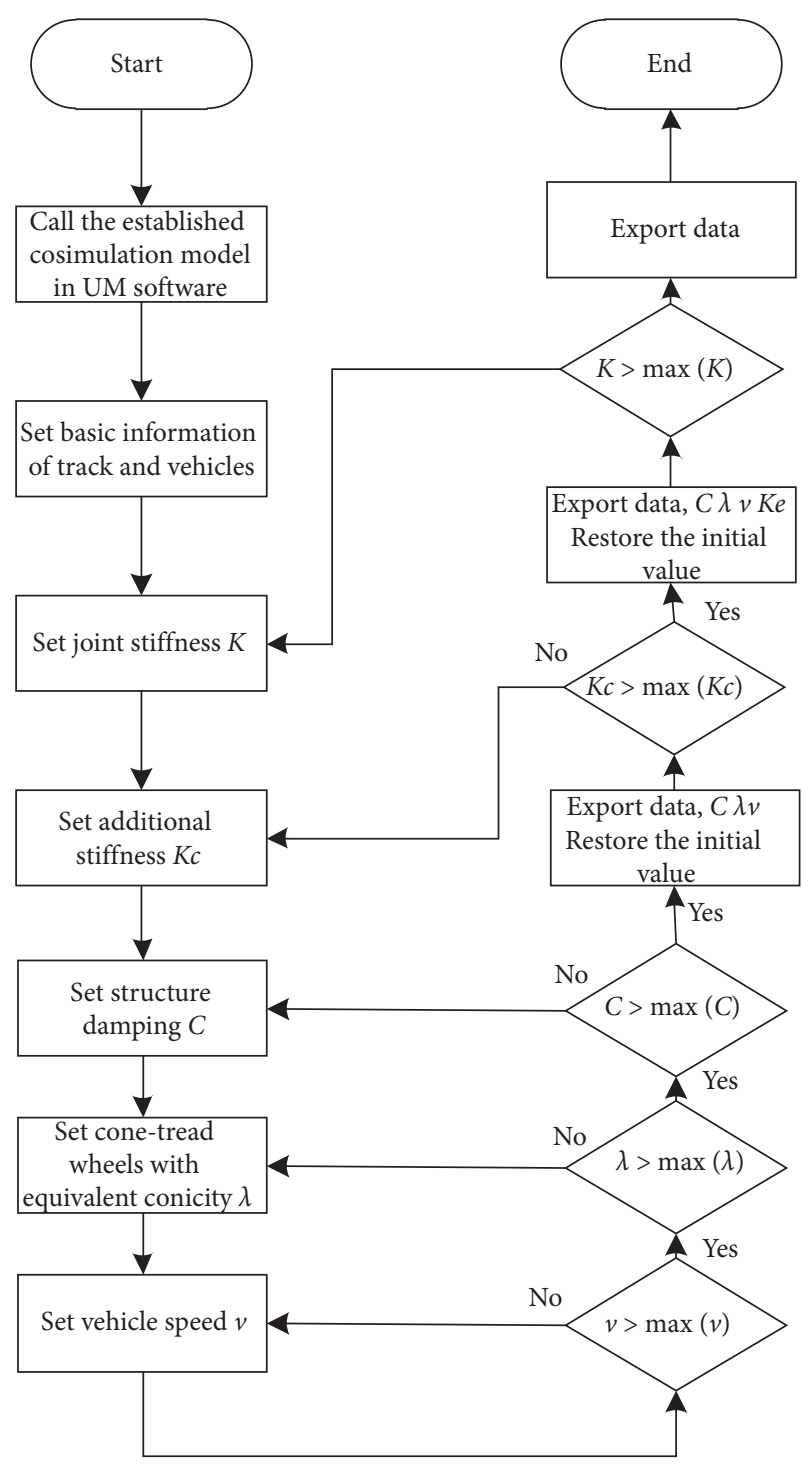

FIGURE 11: Simulation calculation flowchart.

rises, which means the vehicle ride quality decreases. It can be seen that when the structural damping is 0 , the vehicle ride quality is poor due to the lack of the yaw damper to suppress vehicle's hunting. With structural damping increasing, the qualified ride quality space in the low equivalent conicity area expands, and the excellent ride quality space in the high equivalent conicity area expands fast, which means that the vehicle ride quality gradually increases and is sensitive to the equivalent conicity. When the structural damping is greater than $330 \mathrm{kN} \cdot \mathrm{sm}^{-1}$, the qualified ride quality space in the high equivalent conicity area expands significantly and fast. However, there is no significant change in the ride quality space of all levels in the low equivalent conicity area, especially at high vehicle speeds. When the speed is greater than $350 \mathrm{~km} \cdot \mathrm{h}^{-1}$, the vehicle ride quality is only sensitive to the equivalent conicity, but not to structural damping. When the wheels are worn, the structural damping of the yaw damper should be appropriately increased so that to ensure the ride quality of the vehicle at high speed.

Figure 13 shows the calculation results of the joint stiffness being $70 \mathrm{MN} \cdot \mathrm{m}^{-1}$ and the additional stiffness being $4 \mathrm{MN} \cdot \mathrm{m}^{-1}$. It can be seen that when the structural damping is 0 , there is no significant change in the vehicle ride quality space compared to the condition of the additional stiffness being 0 , for there is no damping, and only a small stiffness cannot suppress the vehicle's hunting. With the increase of structural damping, the whole ride quality of the vehicle first increases and then decreases. When the structural damping is smaller than $220 \mathrm{kN} \cdot s \cdot \mathrm{m}^{-1}$, the ride quality of the vehicle is not sensitive to the equivalent conicity. However, the change of the equivalent conicity has a greater impact on the ride quality of the vehicle when the structural damping is greater than $330 \mathrm{kN} \cdot \mathrm{s} \cdot \mathrm{mm}^{-1}$, and the whole vehicle ride quality is significantly improved compared to the condition of the additional stiffness being 0 , which indicates that increasing additional stiffness is beneficial to improve vehicle running ride quality, and structural damping that matches the additional stiffness is also needed.

Figure 14 shows the calculation results of the joint stiffness being $70 \mathrm{MN} \cdot \mathrm{m}^{-1}$ and the additional stiffness being $8 \mathrm{MN} \cdot \mathrm{m}^{-1}$. It can be seen that referring to the two cases of Figures 12 and 13, with the change of structural damping, the change trend of the ride quality space at all levels of the vehicle is quite similar. When the joint stiffness is large and constant with the structural damping being smaller than $330 \mathrm{kN} \cdot \mathrm{s} \cdot \mathrm{m}^{-1}$, the vehicle ride quality is significantly improved compared with the condition of additional stiffness being 0 . When the structural damping is greater than $330 \mathrm{kN} \cdot \mathrm{s} \cdot \mathrm{m}^{-1}$, vehicle ride quality in the high equivalent conicity area improved slightly compared with the condition of additional stiffness being $4 \mathrm{MN} \cdot \mathrm{m}^{-1}$. There is no obvious change in the ride quality of the low equivalent conicity area, and the vehicle ride quality is improved compared to the condition of the additional stiffness being 0 . In a word, the greater the additional stiffness within a certain range is, the better the whole vehicle ride quality is and the less sensitive it is to the equivalent conicity. There is an optimal solution for the additional stiffness value and an optimal damping value matching it.

Figure 15 shows the calculation results of the joint stiffness being $25 \mathrm{MN} \cdot \mathrm{m}^{-1}$ and the additional stiffness being 0 . It can be seen that when the structural damping is 0 , the vehicle's ride quality is poor due to the lack of yaw damper to suppress vehicle's hunting. With the increase of structural damping, the qualified ride quality space in the low equivalent conicity area expands, and the excellent ride quality space in the high equivalent conicity area expands fast. Compared with Figure 12, when the structural damping is lower than $330 \mathrm{kN} \cdot \mathrm{s} \cdot \mathrm{m}^{-1}$, the maximum boundary speed of 


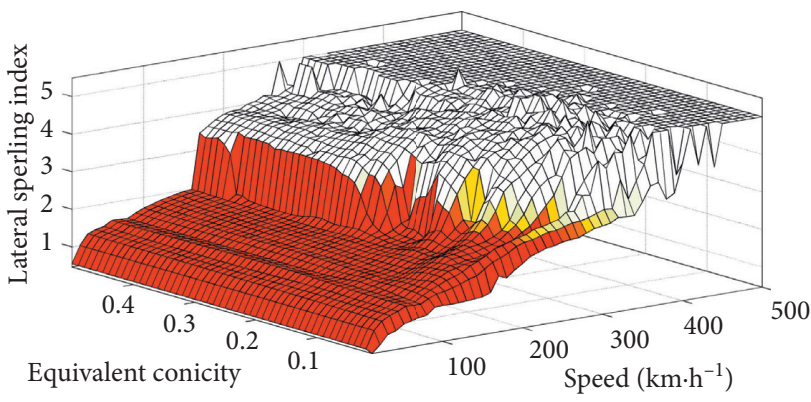

(a)

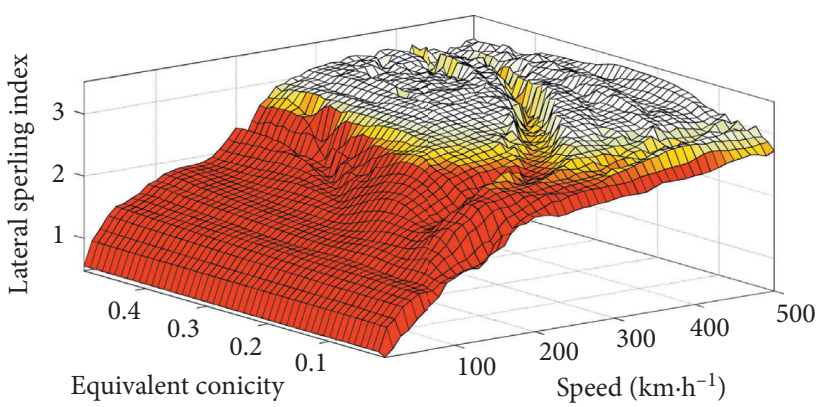

(c)

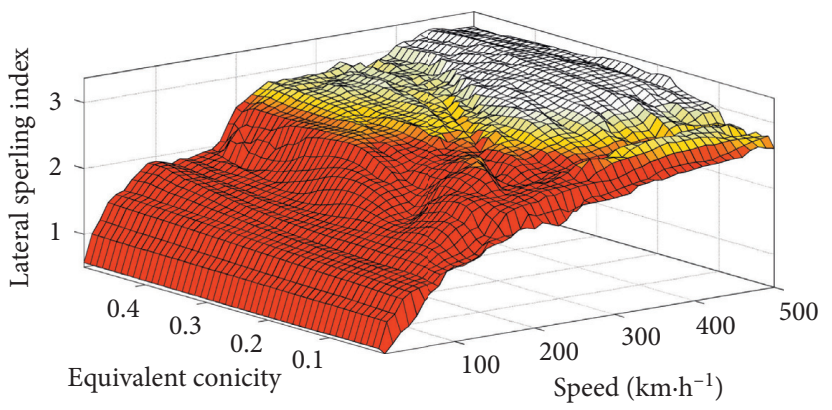

(e)

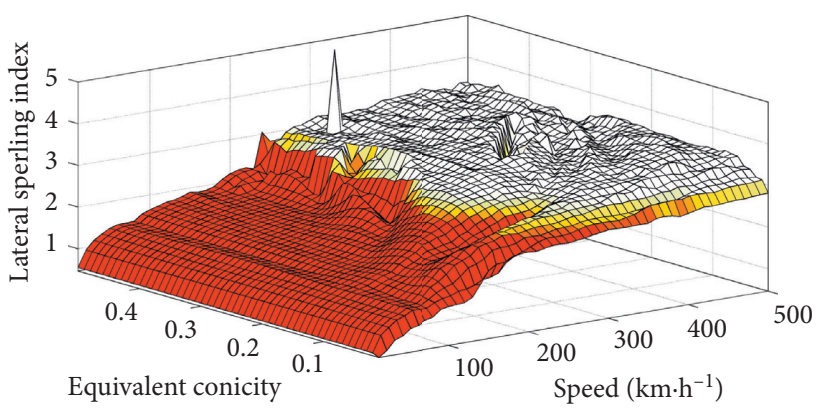

(b)

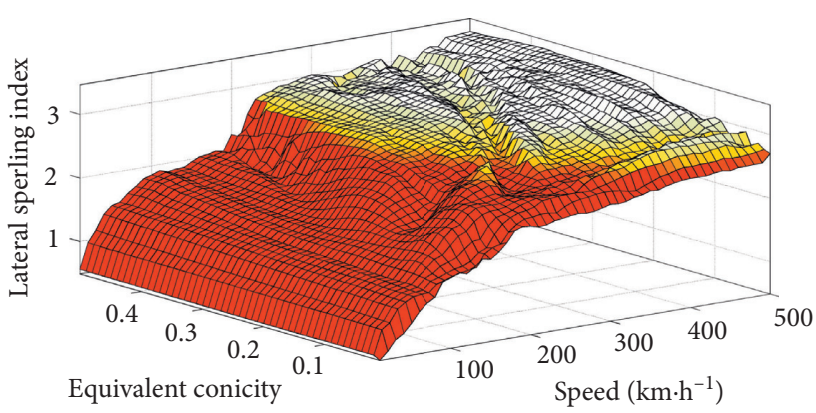

(d)

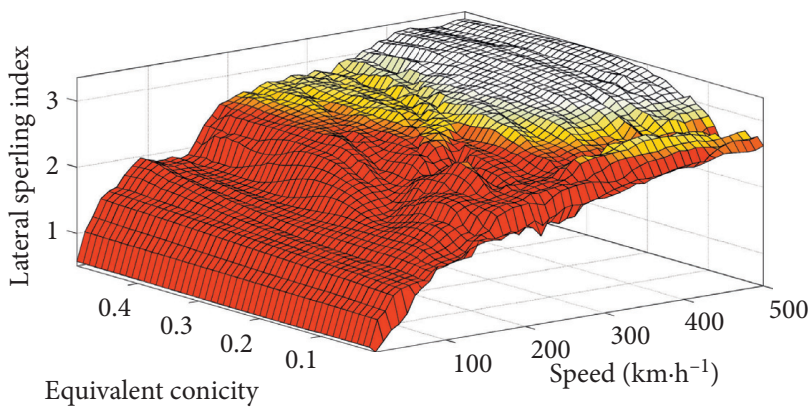

(f)

FIGURE 12: Vehicle ride quality space with joint stiffness of $70 \mathrm{MN} \cdot \mathrm{m}^{-1}$ and additional stiffness of 0 . (a) $c=0$. (b) $c=110 \mathrm{kN} \cdot \mathrm{s} \cdot \mathrm{m}^{-1}$. (c) $c=220 \mathrm{kN} \cdot \mathrm{s} \cdot \mathrm{m}^{-1}$. (d) $c=330 \mathrm{kN} \cdot \mathrm{s} \cdot \mathrm{m}^{-1}$. (e) $c=440 \mathrm{kN} \cdot \mathrm{s} \cdot \mathrm{m}^{-1}$. (f) $c=550 \mathrm{kN} \cdot \mathrm{s} \cdot \mathrm{m}^{-1}$.

the excellent ride quality space slightly increases, which indicates that the vehicle ride quality is slightly improved. When the structural damping is greater than $400 \mathrm{kN} \cdot \mathrm{s} \cdot \mathrm{m}^{-1}$, the expansion rate of ride quality space in high equivalent conicity is faster. It could be concluded that, after the joint stiffness is reduced, the vehicle ride quality is truly improved and is more sensitive to the equivalent conicity and the structural damping, which is consistent with the conclusion obtained in Figure 12.

Figure 16 shows the calculation results of the joint stiffness being $25 \mathrm{MN} \cdot \mathrm{m}^{-1}$ and the additional stiffness being $4 \mathrm{MN} \cdot \mathrm{m}^{-1}$. It can be seen that when the joint stiffness remains unchanged, the vehicle ride quality is significantly improved as the additional stiffness increases compared with Figure 15; when there is a certain additional stiffness and the structural damping remains unchanged, the smaller the joint stiffness is, the higher the ride quality of the vehicle is, compared with Figure 13, which is more obvious when the structural damping is greater than $330 \mathrm{kN} \cdot \mathrm{s} \cdot \mathrm{m}^{-1}$ with the equivalent conicity being greater than 0.2 . It could be concluded that a certain additional stiffness can improve the vehicle ride quality, and appropriately reducing the joint stiffness can expand the ride quality area in the high equivalent conicity area, but a matching damping value is also required.

Figure 17 shows the calculation results of the joint stiffness being $25 \mathrm{MN} \cdot \mathrm{m}^{-1}$ and the additional stiffness being $8 \mathrm{MN} \cdot \mathrm{m}^{-1}$. It can be seen that the effect of additional stiffness on vehicle ride quality is consistent with the results obtained in Figure 14. There is an optimal solution for additional stiffness and an optimal damping value matching it. Compared with Figure 14, when the structural damping and the additional stiffness are constant, the smaller the joint stiffness is, the better the vehicle ride quality is, which is more obvious in the condition that equivalent conicity is large (i.e., wheels are seriously worn) and the structural damping is less than $440 \mathrm{kN} \cdot \mathrm{s} \cdot \mathrm{m}^{-1}$.

From the further analysis of the vehicle's lateral ride quality, it can be seen that, for the vehicle ride quality space at all levels, the wider the spatial distribution is, the better the 


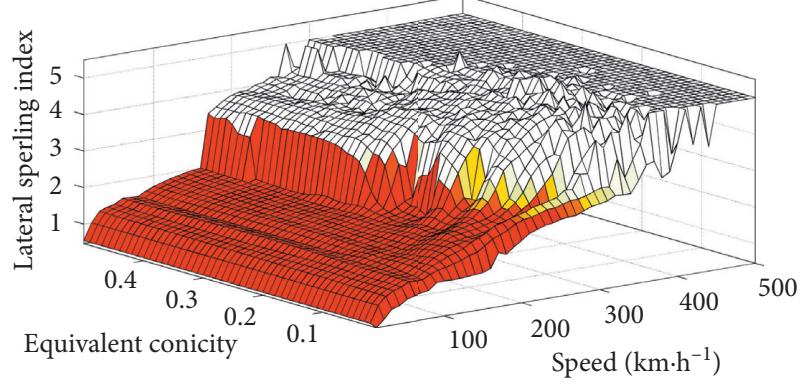

(a)

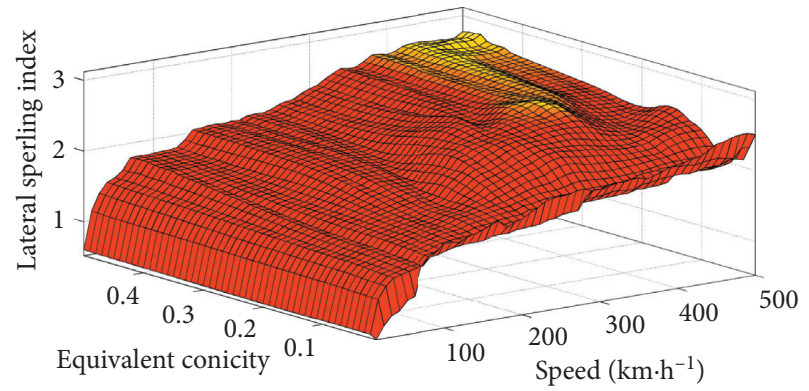

(c)

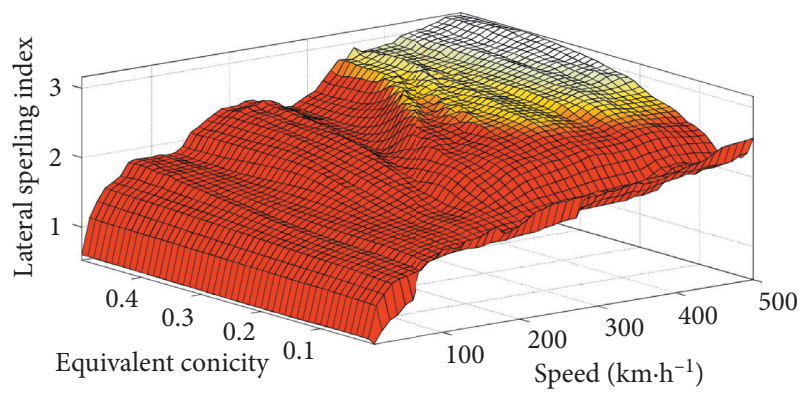

(e)

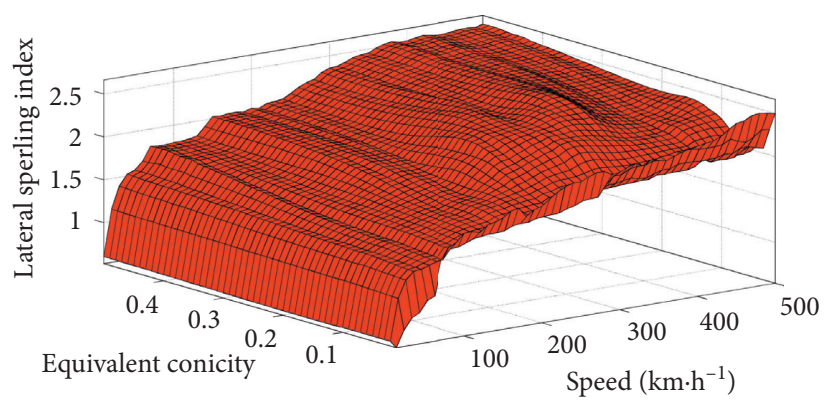

(b)

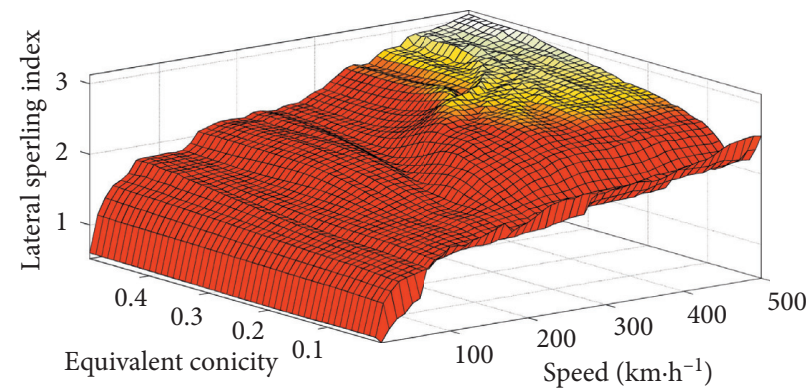

(d)

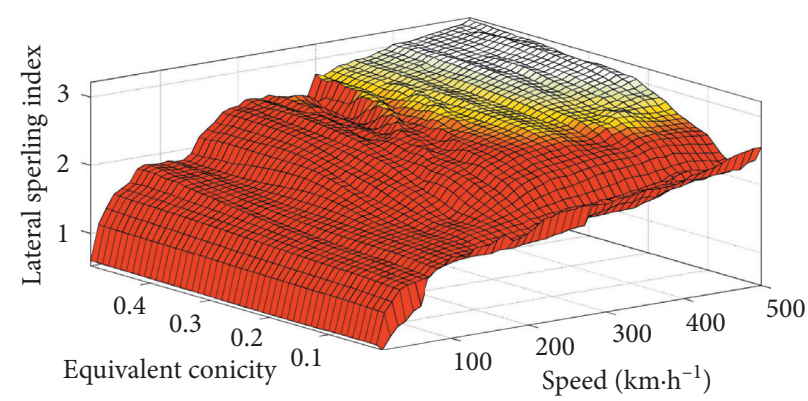

(f)

FIGURE 13: Vehicle ride quality space with joint stiffness of $70 \mathrm{MN} \cdot \mathrm{m}^{-1}$ and additional stiffness of $4 \mathrm{MN} \cdot \mathrm{m}^{-1}$. (a) $c=0$. (b) $c=110 \mathrm{kN} \cdot \mathrm{s} \cdot \mathrm{mm} \mathrm{m}^{-1}$. (c) $c=220 \mathrm{kN} \cdot \mathrm{s} \cdot \mathrm{m}^{-1}$. (d) $c=330 \mathrm{kN} \cdot \mathrm{s} \cdot \mathrm{m}^{-1}$. (e) $c=440 \mathrm{kN} \cdot \mathrm{s} \cdot \mathrm{m}^{-1}$. (f) $c=550 \mathrm{kN} \cdot \mathrm{s} \cdot \mathrm{m}^{-1}$.

vehicle ride quality at all levels are; the faster the space changes with the characteristic parameters, the more sensitive to characteristic parameters the vehicle ride quality at all levels are. With the characteristic parameters of the yaw damper changing, the excellent ride quality space changes faster in the low equivalent conicity area, and the qualified ride quality space changes faster in the high equivalent conicity area. Appropriate additional stiffness can increase the critical speed of the CRH380 B EMU, but a correspondingly matched structural damping value is also needed. Under the existing CRH380 B parameter conditions, when the damping value is smaller than $330 \mathrm{kN} \mathrm{s} \mathrm{m}^{-1}$, there is a certain damping of the yaw damper which is conducive to the ride quality of the vehicle. When the damping value is greater than $440 \mathrm{kN} \cdot \mathrm{s} \cdot \mathrm{m}^{-1}$, the qualified space in the high equivalent conicity area is reduced, and the whole ride quality space in the low equivalent conicity area can hardly be affected by the damping value, which indicates that the damping of the yaw damper should not be too large. Appropriately reducing the joint stiffness of the existing yaw damper is beneficial to improve the vehicle ride quality. The above analysis shows that the ride quality performance of the vehicle could reach a comprehensive optimal state with structural damping being $110 \mathrm{kN} \cdot \mathrm{s} \cdot \mathrm{m}^{-1}$, joint stiffness being $25 \mathrm{MN} \cdot \mathrm{m}^{-1}$, and the additional stiffness being $4 \mathrm{MN} \cdot \mathrm{m}^{-1}$.

\section{Test Analysis and Application}

The calculation results in the previous section are consistent with the yaw damper test of the Wuhan-Guangzhou highspeed railway. In the test, the critical value for evaluating lateral ride quality is set to 2.5 , considering the actual operating conditions of the vehicle. For the yaw damper with different damping coefficients or joint stiffness, when nondriven wheels with a low nominal equivalent conicity are installed, the lateral ride quality of the car body increases; when the driven wheels with a high nominal equivalent conicity are installed, the car body is relatively insensitive to the change of the characteristic parameters of the yaw damper, and the lateral ride quality is smaller compared with the nondriven wheels. The test results show that when the nominal equivalent conicity of the wheel is low, the 


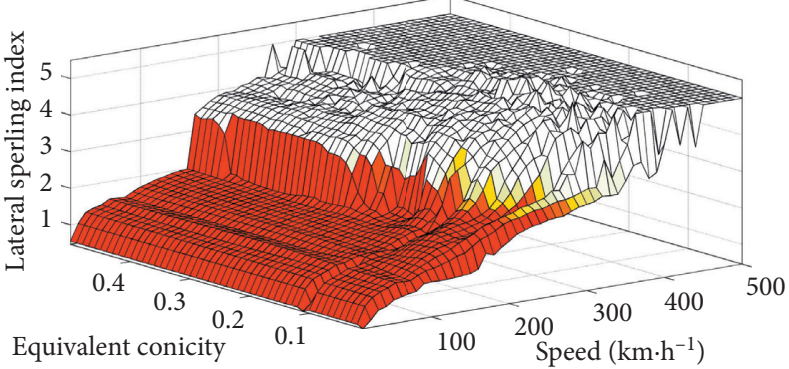

(a)

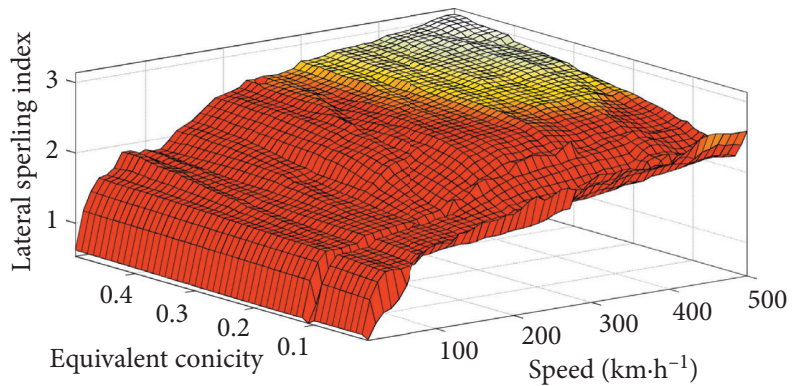

(c)

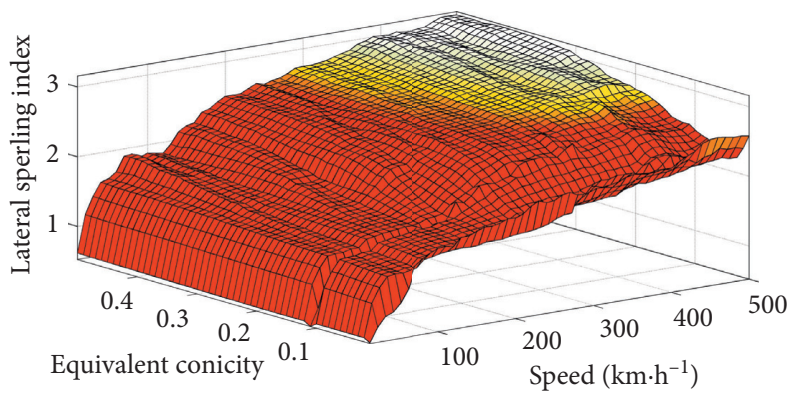

(e)

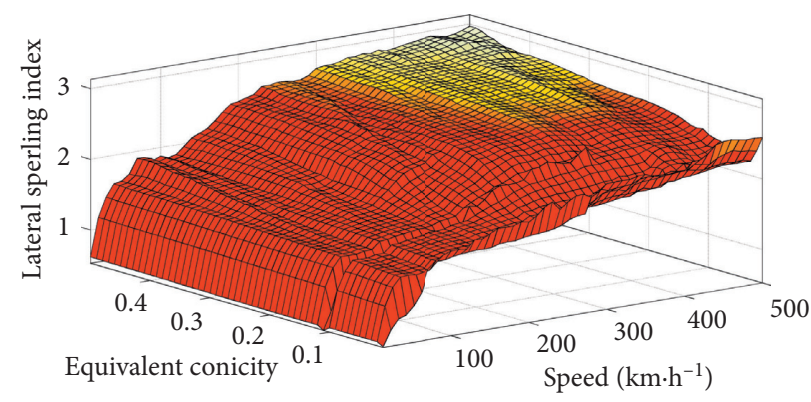

(b)

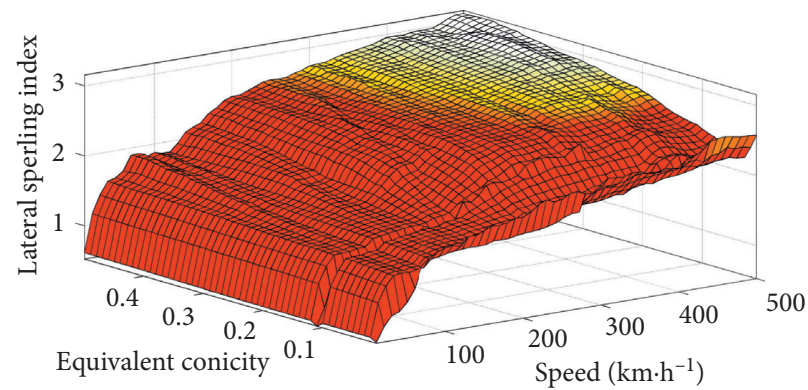

(d)

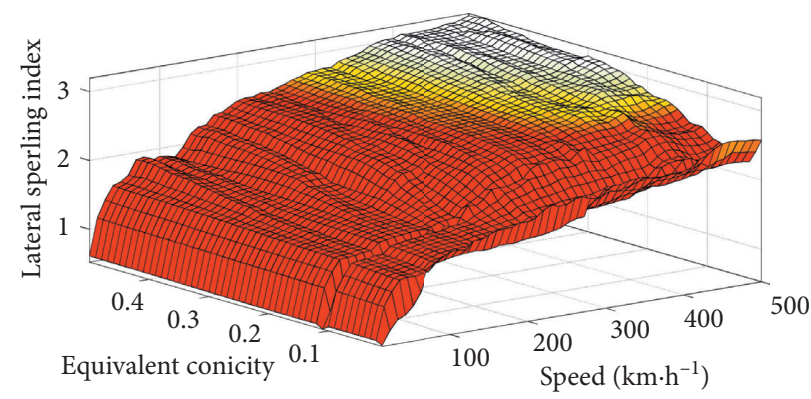

(f)

Figure 14: Vehicle ride quality space with joint stiffness of $70 \mathrm{MN} \cdot \mathrm{m}^{-1}$ and additional stiffness of $8 \mathrm{MN} \cdot \mathrm{m}^{-1} \cdot$ (a) $c=0$. (b) $c=110 \mathrm{kN} \cdot s \cdot \mathrm{m}^{-1}$. (c) $c=220 \mathrm{kN} \cdot \mathrm{s} \cdot \mathrm{m}^{-1}$. (d) $c=330 \mathrm{kN} \cdot \mathrm{s} \cdot \mathrm{m}^{-1}$. (e) $c=440 \mathrm{kN} \cdot \mathrm{s} \cdot \mathrm{m}^{-1}$. (f) $c=550 \mathrm{kN} \cdot \mathrm{s} \cdot \mathrm{m}^{-1}$.

corresponding excellent ride quality is easily affected and changes faster. When the nominal equivalent conicity is higher, the excellent ride quality changes relatively insignificantly and is insensitive to the equivalent conicity, which is consistent with the calculation conclusion.

The optimized parameters of the yaw damper obtained by simulation are applied in the optimization test of the yaw damper of CRH380 B high-cold EMU. By adjusting the damping adjustment device at the bottom of the cylinder of the yaw damper, the damping characteristic parameters of the prototype yaw damper are adjusted to the optimal values in the calculation results so that the new yaw damper is obtained and installed in the EMU. The prototype yaw damper is set to the value of the CRH380 B current yaw damper, and the new yaw damper is set to the optimized values of the characteristic parameters concluded at the end of Section 6. Corresponding speed sensors are arranged in the test to measure the lateral vibration response of the vehicle when the new and prototype yaw dampers are installed. At the same time, the speed-frequency domain method is used to analyse the measured data.
Figure 18 shows the frequency domain analysis of the lateral vibration response, where the red and blue curves correspond to the frequency domain response of the new and prototype dampers, respectively. Figure 18(a) shows the lateral translation of the vehicle body. Figure 18(b) shows the yaw of the vehicle body. Figure 18(c) shows the rolling of the vehicle body. Figures 18(d)-(f) show the lateral translation of the bogie frames and the in-phase and the antiphase yaw of the bogie frames. It can be seen that, after the installation of the new yaw damper, the amplitude of lateral translation of the vehicle body is reduced, and the frequency is reduced; the vibration amplitude of yaw of the vehicle body is reduced, and the frequency is reduced, which is consistent with the change of lateral translation of the vehicle body; there is a new peak amplitude of rolling of the vehicle body, and the value is about $50 \%$ of the yaw of the vehicle body; the vibration amplitude of in-phase yaw of the bogie frames is obviously reduced, the frequency is reduced, and the amplitude of antiphase yaw of the bogie frames is the only one that was reduced, and the frequency is basically unchanged. The increase in vehicle vibration 


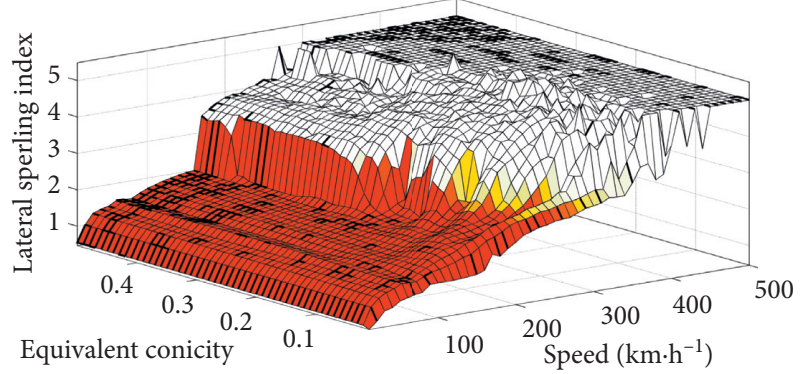

(a)

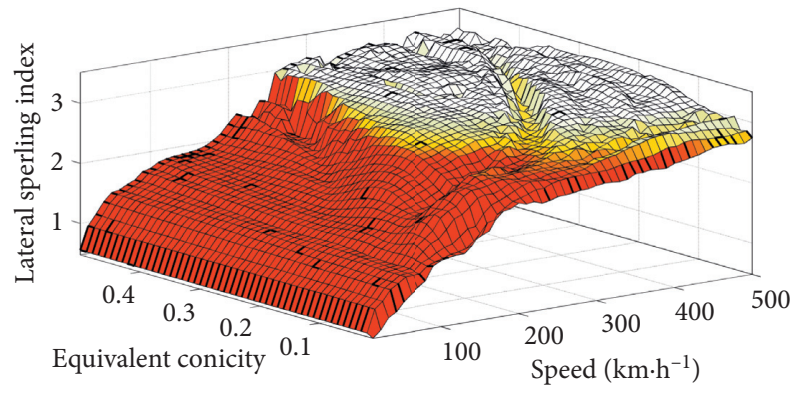

(c)

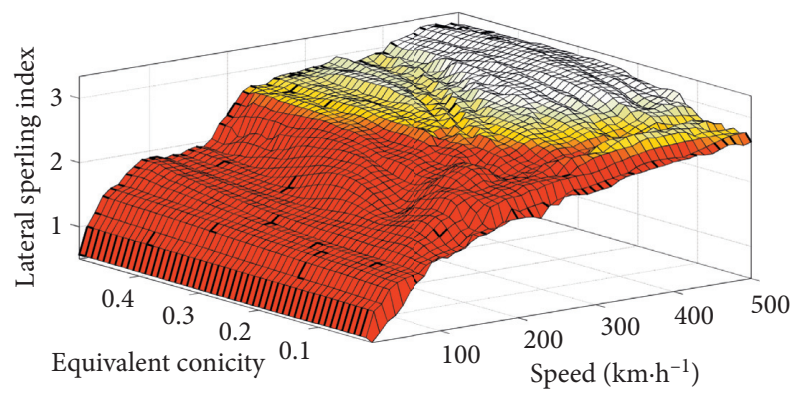

(e)

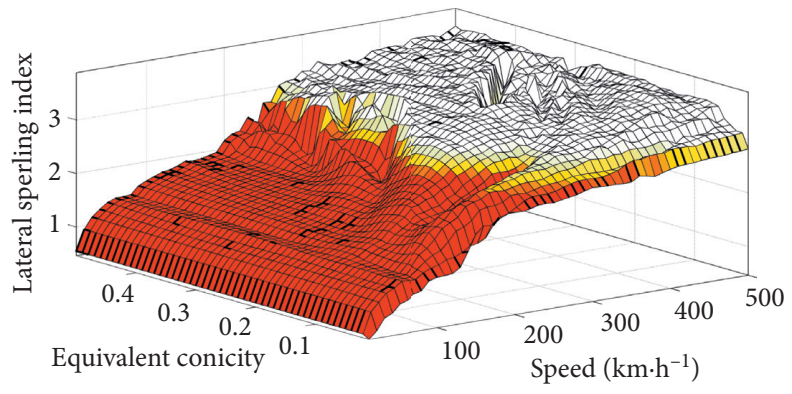

(b)

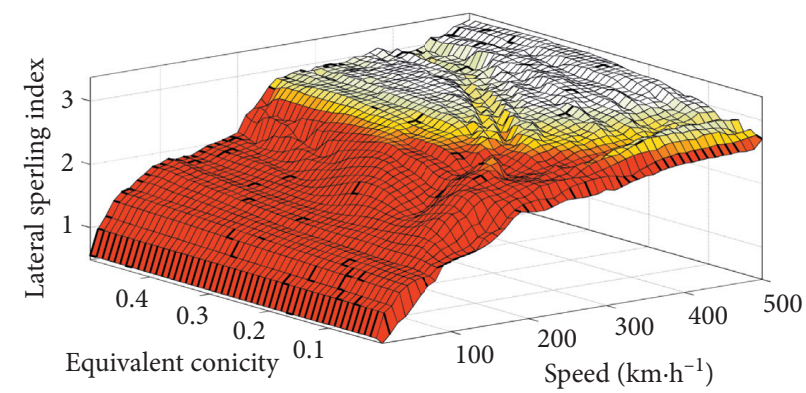

(d)

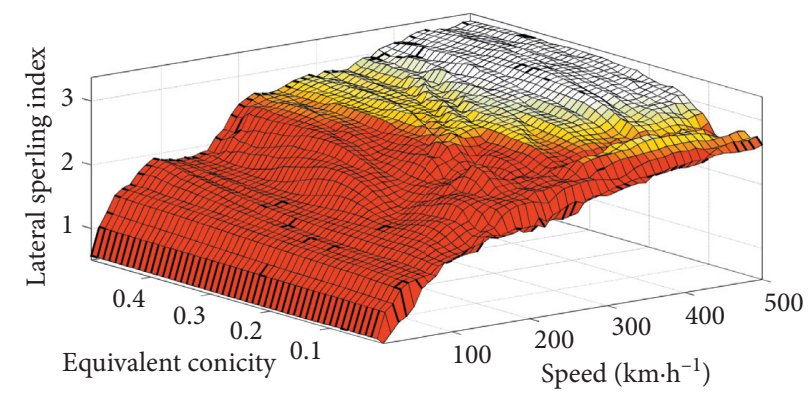

(f)

FIgURE 15: Vehicle ride quality space with joint stiffness of $25 \mathrm{MN} \cdot \mathrm{m}^{-1}$ and additional stiffness of 0 . (a) $c=0$. (b) $c=110 \mathrm{kN} \cdot \mathrm{s} \cdot \mathrm{m}^{-1}$. (c) $c=220 \mathrm{kN} \cdot \mathrm{s} \cdot \mathrm{m}^{-1}$. (d) $c=330 \mathrm{kN} \cdot \mathrm{s} \cdot \mathrm{m}^{-1}$. (e) $c=440 \mathrm{kN} \cdot \mathrm{s} \cdot \mathrm{m}^{-1}$. (f) $c=550 \mathrm{kN} \cdot \mathrm{s} \cdot \mathrm{m}^{-1}$.

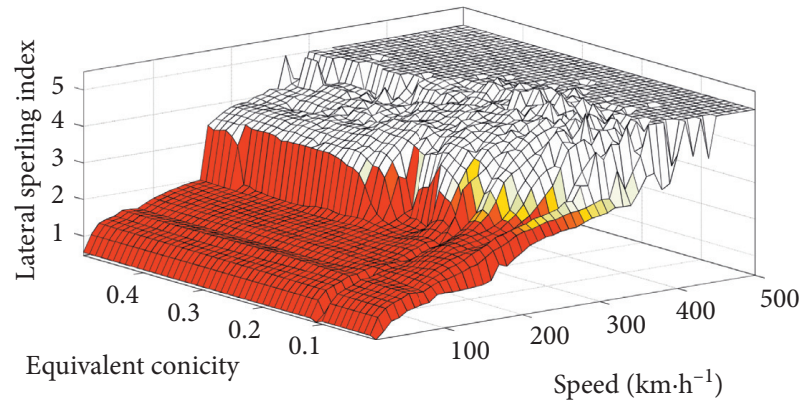

(a)

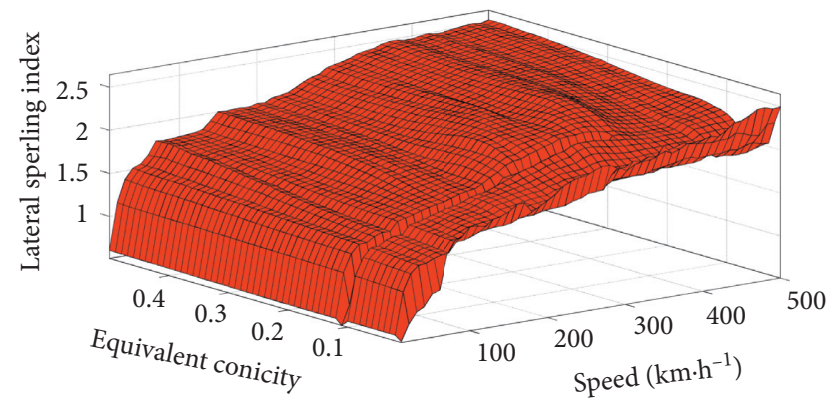

(b)

Figure 16: Continued. 


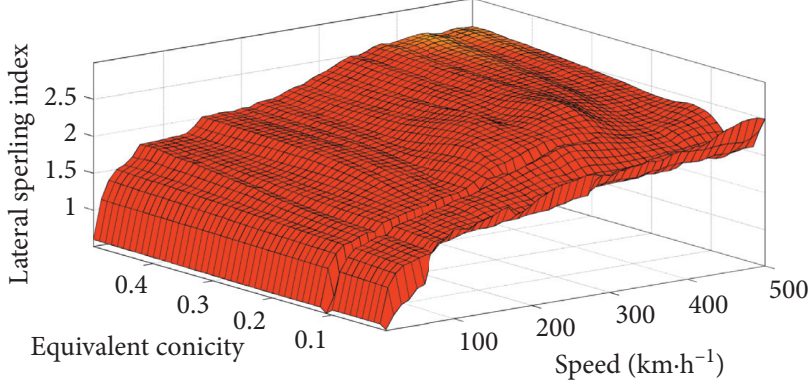

(c)

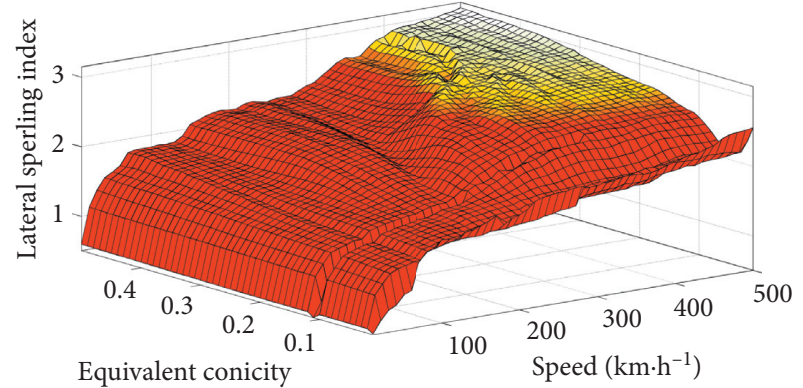

(e)

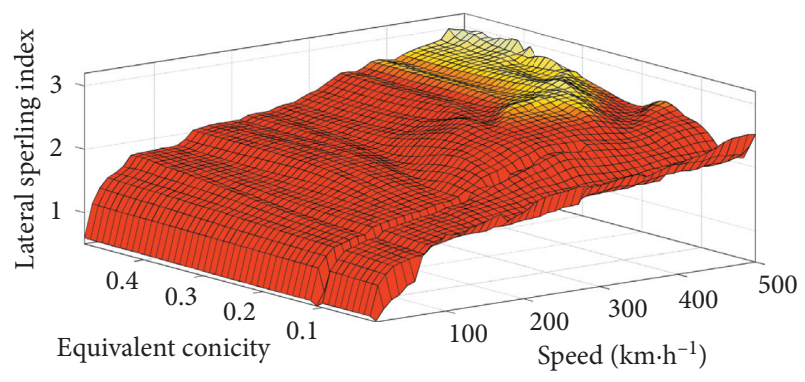

(d)

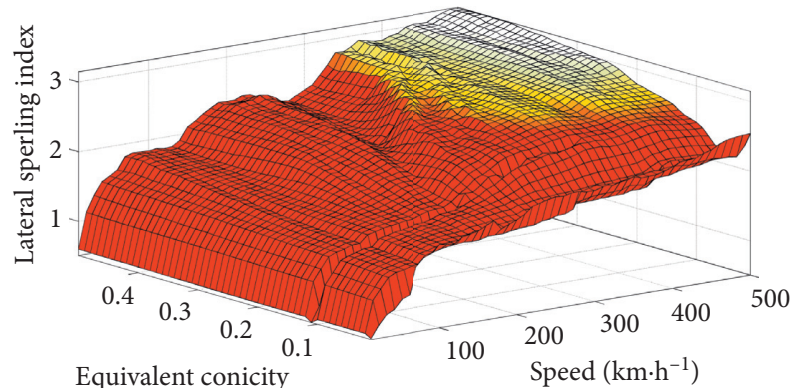

(f)

Figure 16: Vehicle ride quality space with joint stiffness of $25 \mathrm{MN} \cdot \mathrm{m}^{-1}$ and additional stiffness of $4 \mathrm{MN} \cdot \mathrm{m}^{-1}$. (a) $c=0$. (b) $c=110 \mathrm{kN} \cdot \mathrm{s} \cdot \mathrm{m}^{-1}$. (c) $c=220 \mathrm{kN} \cdot \mathrm{s} \cdot \mathrm{m}^{-1}$. (d) $c=330 \mathrm{kN} \cdot \mathrm{s} \cdot \mathrm{m}^{-1}$. (e) $c=440 \mathrm{kN} \cdot \mathrm{s} \cdot \mathrm{m}^{-1}$. (f) $c=550 \mathrm{kN} \cdot \mathrm{s} \cdot \mathrm{m}^{-1}$.

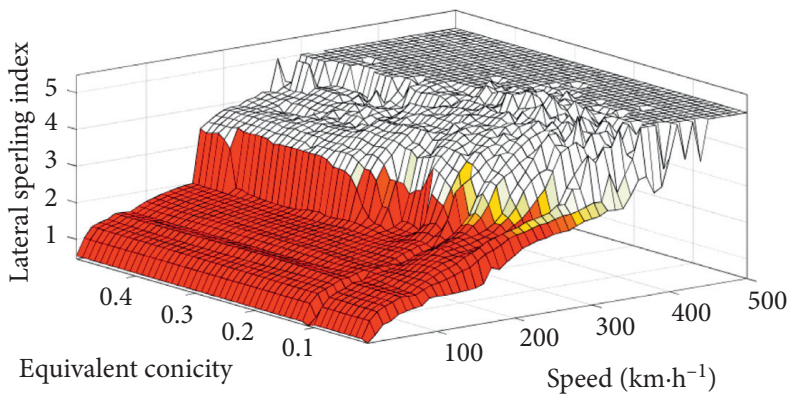

(a)

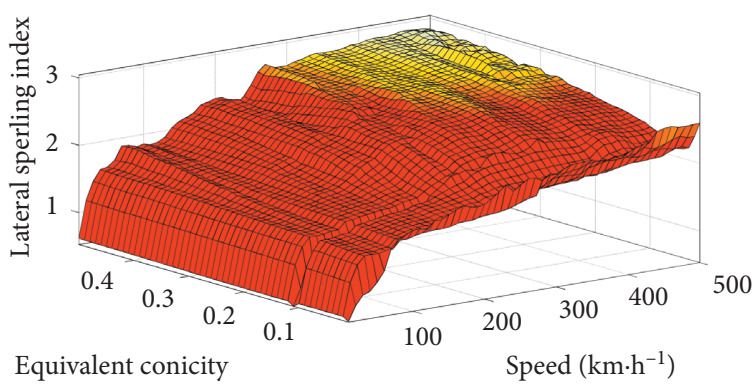

(c)

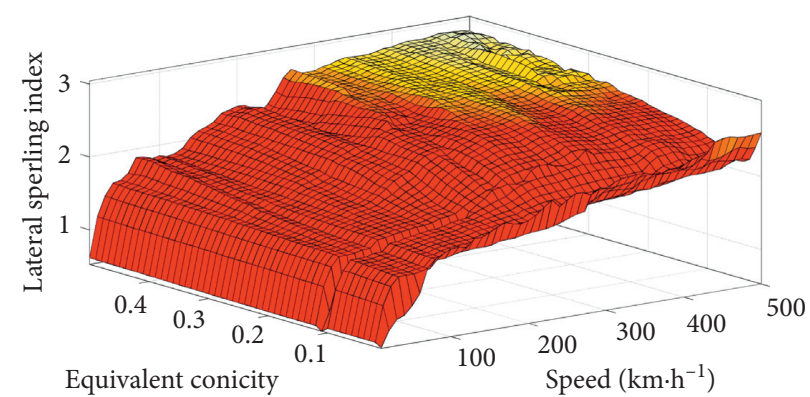

(b)

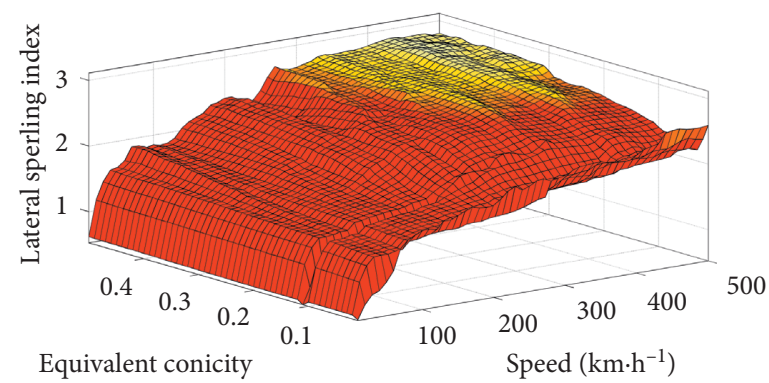

(d)

FIgURe 17: Continued. 


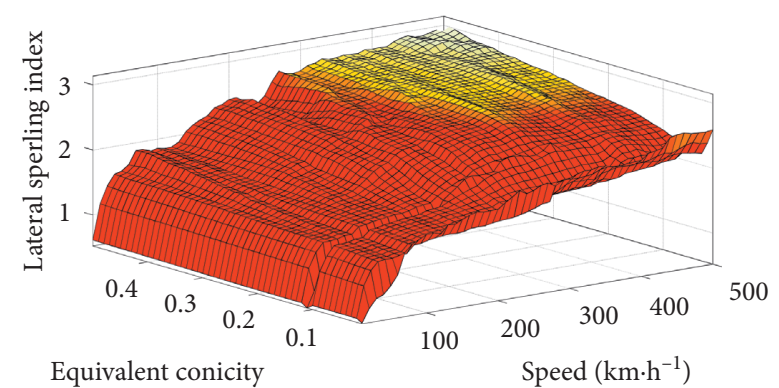

(e)

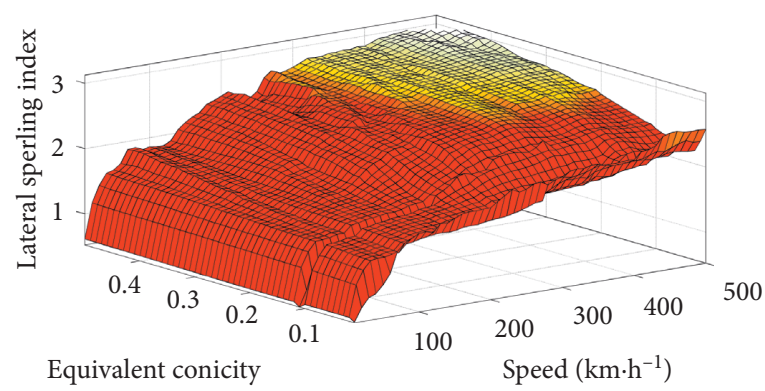

(f)

FIGURE 17: Vehicle ride quality space with joint stiffness of $25 \mathrm{MN} \cdot \mathrm{m}^{-1}$ and additional stiffness of $8 \mathrm{MN} \cdot \mathrm{m}^{-1}$. (a) $c=0$. (b) $c=110 \mathrm{kN} \cdot \mathrm{s} \cdot \mathrm{m}^{-1}$. (c) $c=220 \mathrm{kN} \cdot \mathrm{s} \cdot \mathrm{m}^{-1}$. (d) $c=330 \mathrm{kN} \cdot \mathrm{s} \cdot \mathrm{m}^{-1}$. (e) $c=440 \mathrm{kN} \cdot \mathrm{s} \cdot \mathrm{m}^{-1}$. (f) $c=550 \mathrm{kN} \cdot \mathrm{s} \cdot \mathrm{m}^{-1}$.

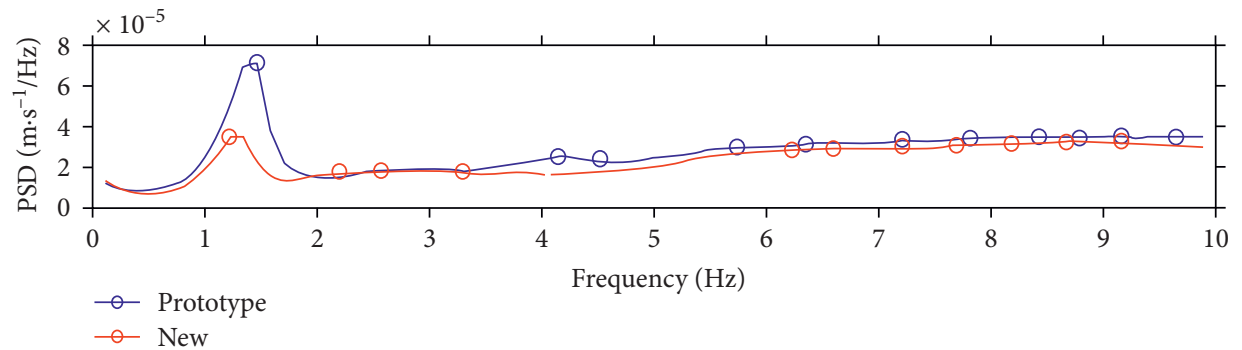

(a)

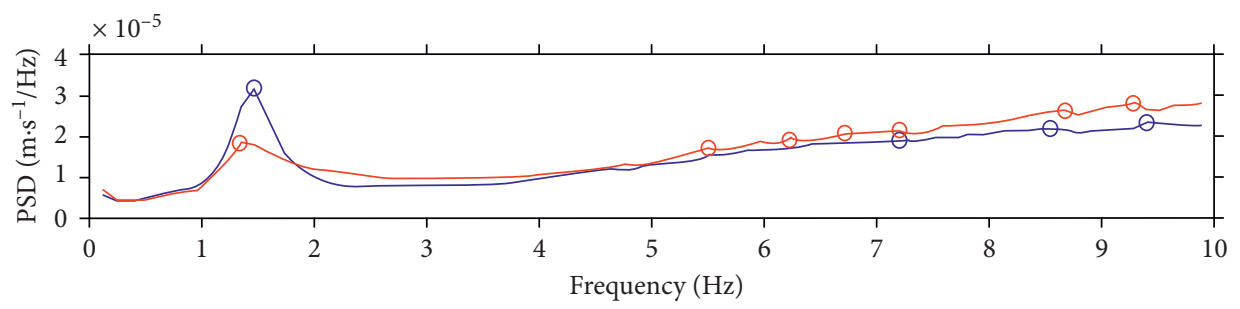

- Prototype
- New

(b)

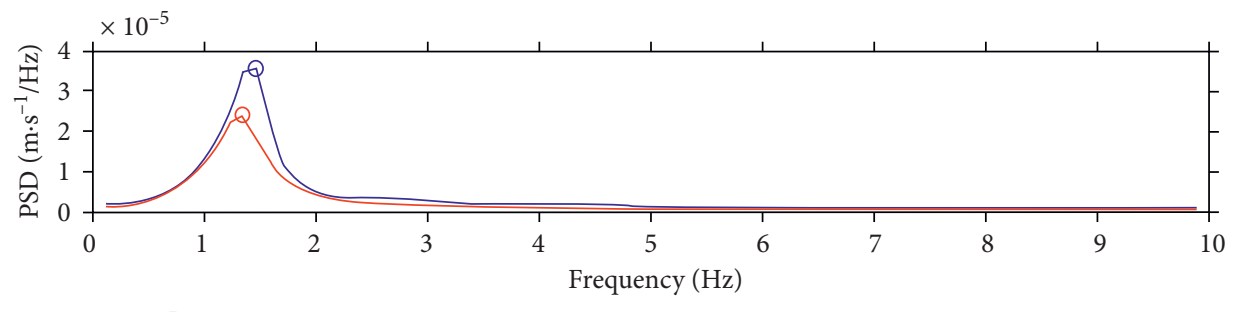

- Prototype

$\rightarrow$ New

(c)

Figure 18: Continued. 


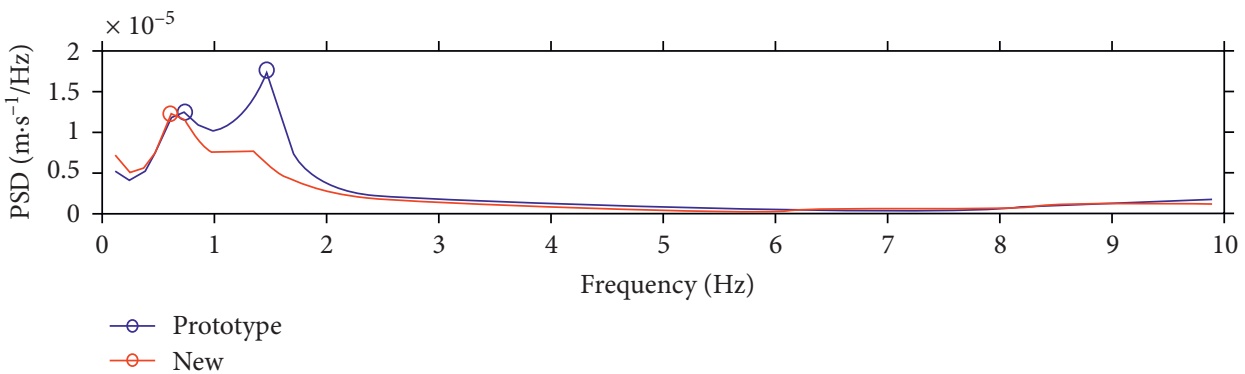

(d)

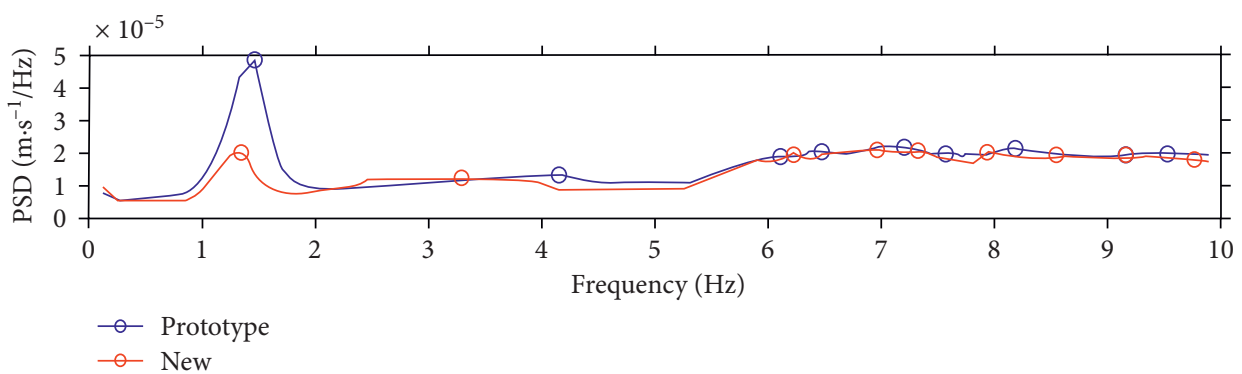

(e)

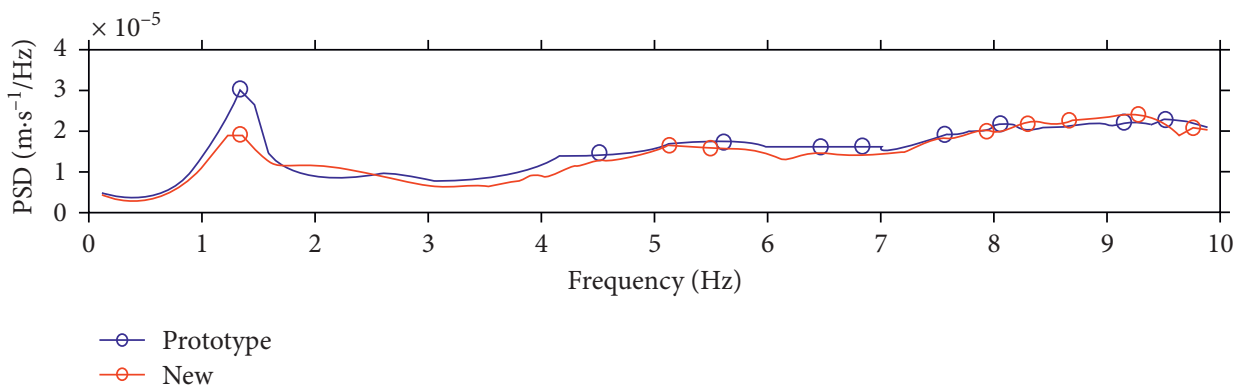

(f)

FIGURE 18: Response of vehicle lateral vibration. (a) Lateral translation of the vehicle body. (b) Yaw of the vehicle body. (c) Rolling of the vehicle body. (d) Lateral translation of the bogie frames. (e) In-phase yaw of the bogie frames. (f) Antiphase yaw of the bogie frames.

mainly corresponds to the yaw of the car body and inphase yaw of the bogie frames. The test results show that the vehicle ride quality increases obviously after the new yaw damper is installed.

\section{Conclusions}

This paper analyses the internal characteristics of the yaw damper, obtains the additional stiffness characteristics of the yaw damper, and establishes an equivalent model of the yaw damper which is then embedded into the vehicle model based on the CRH380 B vehicle parameters. Then, the influence of wheel wear on wheel-rail contact and the change of equivalent conicity are analysed. Besides, the influence of damping and stiffness characteristics and the equivalent conicity of the tread on the vehicle lateral ride quality with the change of vehicle speed are also discussed. Here are the conclusions obtained from this work:

(1) The yaw damper has a certain oil stiffness, which can be expressed by additional spring stiffness. Since the spring and the piston are subject to the same external excitation, the additional stiffness is connected in parallel with the structural damping and then connected in series with the joint stiffness in the equivalent parameter model. The model could not only better reflect the characteristics of yaw damper but also avoid the interference of complicated parameters.

(2) As the wheel wear increases during vehicle operation, local dents appear on the wheel tread, which is often described by the equivalent conicity. The larger wheel wear is, the larger the equivalent conicity is. As wheel wear increases, the nominal equivalent conicity of the wheel increases rapidly in the early stage and changes slowly in the later stage, and the wheel tread can maintain a relatively stable ground profile. The change of the equivalent conicity can better reflect the change of the wheel-rail contact geometry. It could ensure ride quality that the equivalent conicity is maintained within a certain range. 
(3) The wider the spatial distribution of vehicle ride quality at all levels is, the better the ride quality of each level is; the faster the ride quality of each level changes with the characteristic parameters, the more sensitive the ride quality of each level is to the characteristic parameters. When the vehicle is running, there are obvious changes in the excellent ride quality space of the low equivalent conicity area and in the qualified ride quality space of the high equivalent conicity area. Appropriate additional rigidity can improve the vehicle lateral ride quality, and the spatial changes in the high equivalent conicity area are more obvious. When the damping is greater than $440 \mathrm{kN} \mathrm{s} \mathrm{m}^{-1}$, the impact on the vehicle will exist in the platform area so that the damping value should not be too large. Appropriately reducing the current joint stiffness of the yaw damper is beneficial to improve the running ride quality. The comprehensive calculation results show that the optimal damping parameters of the yaw damper are the structural damping of $110 \mathrm{kN} \mathrm{s} \mathrm{m}^{-1}$, the joint stiffness of $25 \mathrm{MN} \cdot \mathrm{m}^{-1}$, and the additional stiffness of $4 \mathrm{MN} \cdot \mathrm{m}^{-1}$. The simulation calculation results are consistent with the test of the CRH3C WuhanGuangzhou high-speed rail. The parameters of the yaw damper optimized by the simulation are used in the CRH380 B high-cold car test. The vehicle ride quality is obviously improved after the new damper is installed.

(4) The rigid body model used in the analysis of vehicle ride quality in this paper can reflect the low-frequency characteristics of car body vibration. Once the flexibility of the car body is considered, the highfrequency vibration characteristics of the flexible car body under the excitation of track irregularities lead to the deterioration of the ride quality of the car, which cannot be reflected only by the rigid body model. This limitation causes the overall calculation results to overestimate the ride quality of vehicle operation. If the rigid-flexible coupling model is used for research, a more comprehensive and realistic conclusion should be obtained. In the follow-up study, the results of this article need to be further improved.

\section{Data Availability}

The numerical data used to support the findings of this study are available from the corresponding author upon request.

\section{Conflicts of Interest}

The authors declare that they have no conflicts of interest.

\section{Acknowledgments}

This work was funded by the National Natural Science Foundation of China (Grant no. 51865009), National Natural Science Foundation of China (Grant no. 52065021), and
Natural Science Foundation of Jiangxi Province (Grant no. 20192BAB206022).

\section{References}

[1] J. He, G. Liu, J. Liu, C. Zhang, and X. Cheng, "Identification of a nonlinear wheel/rail adhesion model for heavy-duty locomotives," IEEE Access, vol. 6, pp. 50424-50432, 2018.

[2] Y. J. Zhou, S. Mei, and S. Freear, "Field programmable gate array implementation of wheel-rail contact laws," IET Control Theory \& Applications, vol. 4, no. 2, pp. 303-313, 2010.

[3] C. Huang and J. Zeng, "Dynamic behaviour of a high-speed train hydraulic yaw damper," Vehicle System Dynamics, vol. 56, no. 12, pp. 1922-1944, 2018.

[4] J. Santamaria, J. Herreros, E. G. Vadillo, and N. Correa, "Design of an optimised wheel profile for rail vehicles operating on two-track gauges," Vehicle System Dynamics, vol. 51, no. 1, pp. 54-73, 2013.

[5] N. Wilson, H. Wu, H. Tournay, and C. Urban, "Effects of wheel/rail contact patterns and vehicle parameters on lateral stability," Vehicle System Dynamics, vol. 48, pp. 487-503, 2010.

[6] H. Zhang, Research on Key Factors of Non-linear Stability of High-Speed Railway Behicle, China Academy of Railway Sciences, Beijing, China, 2014.

[7] Y. Wu, J. Zeng, S. Qu et al., "Low-frequency carbody sway modelling based on low wheel-rail contact conicity analysis," Shock and Vibration, vol. 2020, Article ID 6671049, 17 pages, 2020.

[8] C. Wang, S. Luo, Z. Xu et al., "Research on bogie frame lateral instability of high-speed railway vehicle," Shock and Vibration, vol. 2018, Article ID 8469143, 13 pages, 2018.

[9] J. Sun, M. Chi, X. Jin et al., "Experimental and numerical study on carbody hunting of electric locomotive induced by low wheel-rail contact conicity," Vehicle System Dynamics, vol. 59, pp. 1-21, 2019.

[10] S. L. Liang, M. W. Piao, J. .H. Hao et al., "Study on stability of the high-speed bogie based on three typical wheel treads," China Railway Science, vol. 31, no. 3, pp. 57-63, 2010.

[11] J. Yang, H. Li, M. W. Piao et al., "Suspension nonlinearity of freight bogie based on heuristic model simulation," Journal of Vibration and Shock, vol. 38, no. 3, pp. 116-124, 2019.

[12] M. W. Piao, S. L. Liang, Z. G. Fang et al., "The non-linearity of high-speed bogie and the safety stability margin of high-speed railway vehicles," China Railway Science, vol. 32, no. 3, pp. 86-92, 2011.

[13] Y. Yu, C. C. Zhou, and L. L. Zhao, "Analytical research of yaw damper damping matching for high-speed train," Journal of Mechanical Engineering, vol. 54, no. 2, pp. 159-168, 2018.

[14] A. Alonso, J. G. Giménez, and E. Gomez, "Yaw damper modelling and its influence on railway dynamic stability," Vehicle System Dynamics, vol. 49, no. 9, pp. 1367-1387, 2011.

[15] F. H. Besinger, D. Cebon, and D. J. Cole, "Damper models for heavy vehicle ride dynamics," Vehicle System Dynamics, vol. 24, no. 1, pp. 35-64, 2007.

[16] V. K. Richard, A New Numerial Damper Model Based on the Magic Formula with Application in Railway Vehicle Dynamics, Beijing Jiaotong University, Beijing, China, 2005.

[17] T. H. Jin, Z. M. Liu, and Z. S. Ren, "Adaptability research of variable damping of anti-yaw damper high in speed trail," Journal of Mechanical Engineering, vol. 32, no. 2, pp. 350-358, 2019.

[18] T. H. Jin, Z. M. Liu, and Z. S. Ren, "Study of combination damping characteristics effect of high-speed train damper," 
Journal of South China University of Technology(Natural Science Edition), vol. 46, no. 9, pp. 116-124, 2018.

[19] Z. Qin, S. X. Zhou, and C. L. Sun, "Influence of hydraulic shock absorber characteristic parameters on the critical speed of high-speed trains," Journal of Mechanical Engineering, vol. 53, no. 6, pp. 138-144, 2017.

[20] Z. Xia, J. Zhou, D. Gong, W. Sun, and Y. Sun, "Theoretical study on the effect of the anti-yaw damper for rail vehicles," Proceedings of the Institution of Mechanical Engineers, Part C: Journal of Mechanical Engineering Science, vol. 234, no. 2, pp. 457-473, 2020.

[21] J. Wallaschek, "Dynamics of non-linear automobile shockabsorbers," International Journal of Non-linear Mechanics, vol. 25, no. 2, 3 pages, 1990.

[22] G. Genta and P. Campanile, "An approximated approach to the study of motor vehicle suspensions with nonlinear shock absorbers," Meccanica, vol. 24, no. 1, pp. 47-57, 1988.

[23] W. Schiehlen and B. Hu, "Spectral simulation and shock absorber identification," International Journal of Non-linear Mechanics, vol. 38, no. 2, 2003.

[24] L. Ling, Q. Zhang, X. Xiao, Z. Wen, and X. Jin, "Integration of car-body flexibility into train-track coupling system dynamics analysis," Vehicle System Dynamics, vol. 56, no. 4, pp. $485-505,2018$. 